\title{
Un códice facticio de cancioneros manuscritos del siglo XVI
}

\author{
Ana M. Rodado Ruiz \\ Universidad de Castilla-La Mancha \\ Ana.Rodado@uclm.es \\ https://orcid.org/OOOO-OOO2-04I7-250X \\ Received: $17 / 02 / 2020$; accepted o2/o3/2O2O \\ DOI: https://doi.org/IO.7203/MCLM.7.I6692
}

A factitious codex of sixteenth-century manuscript songbooks

Abstract

A complete codicological analysis of manuscript 2763 of the University Library of Salamanca. This is volume SAıo, in the acronym system proposed by Brian Dutton (I990-9I), a codex that groups two independent cancionero manuscripts of medieval poetry, dating from the early sixteenth century. This exhaustive study of the codex materiality is completed by counting and analysing its selected works and authors, as well as their layout and sequencing. The results allow us to formulate an hypothesis about the genesis of the volume and its complex process of copying and transmission.

\section{KEYWORDS}

Medieval poetry; cancionero manuscripts; material philology; factitious codexs; SAıo; ms 2763 Universidad de Salamanca.

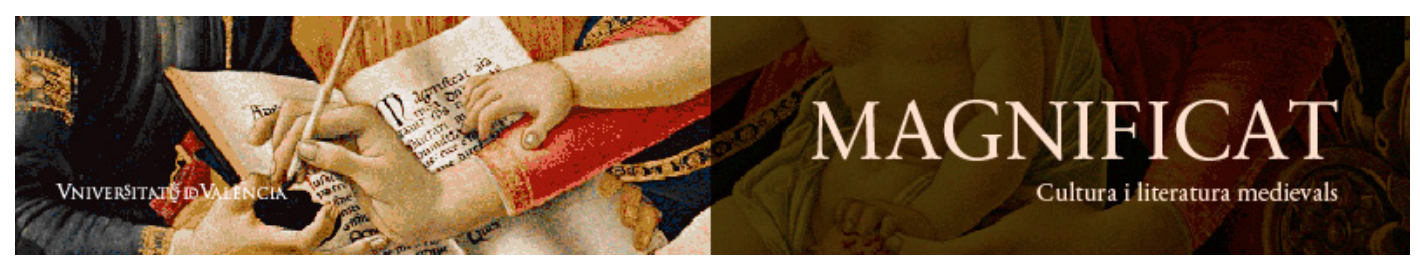

Magnificat Cultura i Literatura Medievals 7, 202O, 59-IOI. http://ojs.uv.es/index.php/MCLM

ISSN $2386-8295$ 
RESUMEN

Se ofrece un completo análisis codicológico del manuscrito 2763 de la Biblioteca Universitaria de Salamanca. Se trata del volumen denominado SAıo en el sistema de siglas propuesto por Brian Dutton (I990-9I), un códice que agrupa dos cancioneros manuscritos independientes de poesía medieval, fechables en la primera mitad del siglo xvi. El estudio exhaustivo de la estricta materialidad del códice se completa con el recuento y análisis de las obras y autores seleccionados, así como de su disposición y secuenciación. Los resultados permiten formular una hipótesis argumentada acerca de la génesis del volumen y de su complejo proceso de copia y transmisión.

PALABRAS CLAVE

Poesía medieval; cancioneros manuscritos; filología material; códices facticios; SAıo; ms 2763 Universidad de Salamanca.

Ana M. Rodado Ruiz. 2020. 'Un códice facticio de cancioneros manuscritos del siglo XvI', Magnificat Cultura i Literatura Medievals, 7: 59-IOI, DOI: https://doi.org/IO.7203/MCLM.7.I6692 $($ cc) B

Este trabajo se enmarca en el proyecto «Cancionero, Romancero y Fuentes Impresas» del Ministerio de Economía, Industria y Competitividad (FFI2Or7-863I3-P), financiado por la Agencia Estatal de Investigación (AEI) y el Fondo Europeo de Desarrollo Regional (FEDER).

\section{TABLA DE CONTENIDOS}

I Historia del manuscrito: transmisión patrimonial - 62

2 Análisis externo - 64

$$
\text { 2.I Marcas de agua y cuadernos - } 66
$$

2.2 Impaginación y análisis paleográfico -67

2.2.I SAioa -67

2.2.2 SAıоb - 69

3 Constitución interna, génesis y cronología $-7^{2}$

3.I SA1оa $-7^{2}$

3.2 SAıb - 75

4 Conclusiones $-7^{8}$

5 Obras citadas - 80

6 Apéndice r: Índice de SAroa - 83

7 Apéndice 2: Tablas secuenciales de obras y autores -84 


\section{के⿻丷木}

$\mathrm{H}$ ace ya más de medio siglo que algunos estudiosos de la literatura medieval y renacentista advirtieron el error de facto que suponía defender como axioma histórico-cultural la existencia de una quiebra de la poética cancioneril a principios del siglo XVI, para ser sustituida por la nueva y moderna lírica italianizante. Rafael Lapesa, entre otros, defendía la génesis de la poesía áurea como fruto de la confluencia de la tradición cancioneril del siglo XV y principios del XVI con la poesía italianista, representada por Boscán y Garcilaso (ı982 [ı962]: I45), en la línea de lo que José Manuel Blecua, pocos años antes, había definido como convivencia y síntesis de tradiciones (I952: 24). Buena prueba de la inexistencia de una fractura sustancial entre ambos periodos literarios son los cancioneros manuscritos e impresos que siguen manteniendo viva la tradición lírica cortesana -dentro y fuera de la península- en las primeras décadas del siglo XVI. Cuando la imprenta ya se impone con fuerza y comienza a sustraer espacio a la transmisión manuscrita en un proceso continuo, dinámico y sin retorno, enseguida crecerá el número de repertorios impresos que, como los manuscritos, representan en esos años la convivencia armónica de ambas poéticas, italianizante y medieval. Algunos antólogos combinan autores de la vieja escuela con los contemporáneos más conocidos y demandados; ${ }^{\mathrm{I}}$ otros, por el contrario, seleccionan únicamente piezas de poetas antiguos y modernos de la tradición cancioneril en caprichosa mezcolanza. Uno de estos códices es el objeto de estudio de este trabajo.

El manuscrito ${ }_{27} 63$ de la Biblioteca General Histórica de la Universidad de Salamanca es un códice facticio que contiene dos cancioneros castellanos datables en las primeras décadas del siglo XVI. ${ }^{2}$ Se trata de dos cancioneros colectivos independientes que fueron encuadernados juntos en fecha incierta, debido, seguramente, a la pérdida de folios en el inicio del segundo de ellos y, sin duda, a la incuria de quien pensó que se trataba de una única colectánea de poesía medieval, incompleta y deteriorada. El mal estado general del códice -con roturas por efecto de la corrosión de la tinta en la primera parte, y manchas de humedad, sobre todo en la segunda- así como la presencia de varias manos en cada repertorio, además de otros problemas relacionados con la mezcla de autores y obras de distinta cronología, dificultan el estudio de su génesis, fases de copia y posibles entornos de elaboración y recepción. A estos inconvenientes se añaden otros, también graves, que solo afectan al segundo cancionero: la importante pérdida de folios y un torpe desorden de encuadernación, con la consiguiente ruptura de la secuencia de cuadernos y las complicaciones que de ello se derivan.

En este trabajo se aborda por primera vez el análisis codicológico y paleográfico del manuscrito completo, y se ofrece una hipótesis argumentada acerca de la génesis de ambas colectáneas, con el fin de despejar los diferentes problemas que presentan.

I. Así ocurre en algunos de los cancioneros de poesías varias del siglo XvI que se guardan en la Biblioteca Nacional de Madrid o en la Biblioteca Real, entre otras instituciones, y que desde hace tres décadas están editando José J. Labrador Herráiz y Ralph A. DiFranco.

2. Agradezco la amabilidad de todo el personal de la Biblioteca General Histórica de la Universidad de Salamanca y, especialmente, la gentileza de su directora, al facilitarme la consulta de este códice. 


\section{Historia del manuscrito: transmisión patrimonial}

$\mathrm{E}_{\mathrm{n}}$ la parte superior del primer folio, justo encima del título del índice incompleto del primer cancionero, una anotación a mano anuncia que el códice perteneció al Colegio Mayor de Cuenca de la Universidad de Salamanca; asimismo, la contratapa y el vuelto de la primera hoja de guarda conservan signaturas que indican el paso del códice por la Biblioteca del Palacio Real de Madrid, antes de ser devuelto a la Biblioteca Universitaria de Salamanca, en donde se guarda desde 1954 .

El Colegio Mayor de Santiago el Zebedeo o de Cuenca -así llamado por haber sido fundado por Diego Ramírez de Villaescusa, obispo de Cuenca- comenzó a funcionar en torno al año I5oo, fecha de su fundación y de su incorporación a la Universidad de Salamanca, aunque no existiera edificio para albergar a los colegiales hasta enero de $5_{5} \mathrm{I} 8$ y no se obtuvieran las bulas de aprobación del papa Adriano VI hasta I523 (Carabias Torres I983: 58-59). Ello permite deducir que fue en ese lapso temporal (I5I8-I523) cuando se pudo empezar a proyectar la biblioteca, es decir, cuando se dispuso de un lugar adecuado y establecido para tal servicio y se hubo recibido la confirmación papal. En todo caso, no queda constancia documental de los libros que formaron la biblioteca original ni de que Ramírez de Villaescusa hubiera aportado o donado sus propios libros a tal efecto (Beltrán de Heredia r971: 4O5-429). Sí consta la incorporación de la biblioteca de Lorenzo Ramírez de Prado ya en el siglo XVII, uno de los más insignes bibliófilos españoles (Entrambasaguas I943; Sánchez Mariana I993: 49-5I), pero en ella no se encontraba nuestro códice ni tampoco los manuscritos que lo integran por separado, al menos el primero de ellos. ${ }^{3}$ De cualquier modo, si a partir del análisis codicológico externo e interno, las hipotéticas fechas de copia para ambos repertorios apuntan a la segunda década del siglo como término post quem -no antes de I5IO, al menos para los últimos estadios del primer cancionero, según se verá más adelante- y teniendo en cuenta el año de recepción de la bula papal, así como el hecho de que no serían los libros más requeridos en la biblioteca colegial, es factible deducir que los cancioneros que forman SAto no podrían haber llegado antes del segundo tercio del siglo XVI.

En las dos centurias siguientes se va incrementando progresivamente el número de libros -en su mayoría, impresos- en la biblioteca del Colegio de Cuenca, hasta llegar a convertirse en la segunda más importante de los colegios salmantinos tras la de San Bartolomé (Carabias Torres I983: I45), ${ }^{4}$ pero no existen registros de adquisiciones o donaciones. Será en el reinado de Carlos III cuando se lleve a cabo el inventario de libros manuscritos e impresos de las bibliotecas de los Colegios Mayores, coincidiendo con la primera fase de la reforma de tales centros universitarios impulsada por este monarca. En marzo de iz7r se envía al obispo de Salamanca, Felipe Bertrán, una Real Cédula, acompañada de la correspondiente instrucción, con el fin de proceder a la inspección de los Colegios Mayores. En dicha instrucción se recoge el procedimiento que debía seguirse en las bibliotecas: se especifica que el comisario y el escribano debían rubricar la primera y la última hoja escritas de cada manuscrito, y reseñar cuántas había útiles, así como dejar constancia del número de códices que se guardaban en cada Colegio (Mestre Sanchis et al. ed. 2002: 69-75).

3. En el inventario de la biblioteca, dentro de la sección de obras de poetas en lenguas vulgares y libros en folio, figura una entrada que dice: «Coplas varias antiguas, y doctrinalias, de varios» (Entrambasaguas 1943: 2, 6o). Sin duda la indicación es inespecífica, pero por lo mismo, no se debe descartar que pudiera tratarse de SAıob, posiblemente acéfalo y sin título ni rúbrica inicial como cuando se encuadernó con el otro cancionero.

4. La mayoría de los colegiales eran estudiantes de Derecho o Teología, y hacían uso continuo de los fondos de la biblioteca (aunque también de sus propios libros), ya que la de la Universidad era deficiente y permaneció cerrada algunas temporadas; «de ahí que tuvieran un especial cuidado en la organización y conservación de los libros» (Carabías Torres I983: I45, I47). Obviamente, los cancioneros serían considerados libros de entretenimiento, aunque el primero de los manuscritos del códice (SAıoa) contiene varias piezas de poesía política y moral, de indudable interés educativo. 
Estos datos procedimentales permiten deducir que fue en la biblioteca del Colegio Mayor y no en la de Palacio donde se fusionaron los dos cancioneros de SAto en un único códice, ya que en los folios ir y i63v figuran las firmas del escribano y el comisario que revisaron este y otros códices de la institución y -lo que es más importante- en el folio i63v anotaron las hojas totales útiles del manuscrito, tal como se requería en la Instrucción: I62, según los encargados de la inspección (sin computar el folio inicial, que contiene un índice parcial del primer cancionero). Este número solo puede corresponder al total de folios de los dos cancioneros, y no solo al del segundo, pues, suponiendo que por entonces aún no hubiera sido mutilado, estuviera completo y figurara como manuscrito independiente en la biblioteca del Colegio, el total de folios resultante de la suma de los 69 conservados - por tanto, útiles; después hay uno final en blanco- más los 66 presumiblemente perdidos, es I35. Además, no existe ningún registro individual de este segundo cancionero en los índices de manuscritos del Colegio Mayor de Cuenca.

En I798, durante el reinado de Carlos IV, se decidió el cese y extinción de los Colegios Mayores de Salamanca y se dispuso la amortización de los bienes muebles e inmuebles, entre los cuales se hallaban sus ricos fondos bibliográficos. ${ }^{5}$ El obispo de Salamanca, Antonio Tavira y Almazán, fue el encargado de realizar un catálogo exhaustivo de los manuscritos de los cuatro colegios salmantinos y de trasladar las bibliotecas al Palacio Real de Madrid en I803. A su «Indice de los libros MSS. que estaban en el Colegio de Cuenca», ${ }^{6}$ de fecha indeterminada, es preciso sumar otro Índice de manuscritos realizado por el colegial Dr. Andrés Navarro y fechado en I782, como fuente indispensable para estudiar la historia patrimonial de SAro. Anoto a continuación las entradas correspondientes en ambos índices:

I. Índice de Tavira y Almazán: «Cancionero antiguo. Contiene cantares y decires de casi todos los antiguos poetas del siglo XV y da principio por la traducción en verso de los Salmos Penitenciales que hizo Diego de Valera. Fo, 1.» [diapos. I27-I28, BDH, BNE, ms. 353, pp. 249-250]. Ms. del siglo XVIII, de fecha indeterminada.

2. Índice del colegial Andrés Navarro: Índice de mss del Col. de Cuenca (I782): «Salmos: Poesías manuscritas» [;8-120?]

El segundo registro no aporta más información que la breve referencia a la obra de Valera que abre el primer cancionero. En cambio, el Índice de Tavira registra precisamente el título que figura hoy en el lomo del manuscrito (Cancionero antiguo) y especifica que recoge cantares y decires de casi todos los antiguos poetas del siglo $\mathrm{XV}$, descripción exagerada si solo se refiere al primer manuscrito -pues este recoge la obra de Guillén de Segovia y de algunos otros poetas con él relacionados, además de la de Hernando Colón, que no puede catalogarse precisamente como poeta antiguo del siglo $X V$-, pero muy ajustada si hace referencia al conjunto de los dos cancioneros que, en efecto, recogen una amplia muestra de la obra de poetas pertenecientes a distintas generaciones. Es posible pensar que Tavira registrara el códice cuando ya había sido encuadernado en la Biblioteca de Palacio (el índice usa el imperfecto «...libros MSS. que estaban en el Colegio de Cuenca») y de ahí la coincidencia en el título; pero es poco probable, pues en otros manuscritos catalogados no existe tal

5. El magnífico edificio del Colegio Mayor de Cuenca, de estilo plateresco, fue destruido en la guerra de la Independencia (Martín Hernández r96ı: 30-40; Carabias Torres r983: 58-59).

6. Forma parte del Indice de los libros manuscritos de los colegios mayores de San Bartolomé, Cuenca, el Arçobispo y Oviedo de Salamanca, por Antonio Tavira y Almazán (ms. 4404, BNE, pp. 249-25O, nº 353); véase también el Índice de los manuscritos que se hallan en la Biblioteca del Colegio Mayor de Cuenca de la Universidad de Salamanca, ms. copia del Dr. Andrés Navarro. Ambos índices están digitalizados por la BNE (http://go.uv.es/smSxMgC y http://go.uv. es/oGgxiXK). 
coincidencia. Por tanto, no se puede descartar que ese fuera el título asignado a los dos manuscritos juntos, ya unidos en Salamanca, y formando el códice facticio que fue trasladado a Madrid. Pudo ser una referencia genérica del propio Tavira que tomaron como título los encuadernadores, pues, efectivamente, desde la perspectiva de los eruditos dieciochescos, se trataba de un «cancionero antiguo» con obras de «antiguos poetas». Los encargados de encuadernar el códice -en pasta española, como el resto de los libros procedentes de Salamanca-incorporaron en el lomo ese título. Por su parte, los responsables de elaborar MNI3 (Moreno 20I2) -proyecto de formación de un cancionero general del siglo XV, a principios del siglo XIX (I8Oz)- tomaron obras de las dos partes de SAio, pues ya formaban un único códice, como se ha comprobado.

La devolución de los libros de los antiguos Colegios Mayores a la Universidad de Salamanca que habían sido reclamados sin éxito en muchas ocasiones- fue un logro extraordinario del rector Antonio Tovar en 1954 (Fink-Errera I959: 90). Se aprovechó entonces el complejo y ambicioso proyecto de organización de los actos conmemorativos del séptimo centenario de la Universidad y se consiguió el compromiso personal de Franco, a quien se había ofrecido la investidura como doctor honoris causa. Así llegan en aquel año «los primeros quinientos códices y manuscritos de los antiguos Colegios Universitarios de Salamanca, que por decisión del caudillo se reintegran a la Universidad después de haber permanecido durante más de siglo y medio en la Biblioteca Real del Palacio de Oriente» (Ramos Ruiz 20o9: 248).

\section{Análisis externo}

$\mathrm{D}$ esde las primeras noticias de Mussafia (I9O2) o Wittstein (I9O7) a comienzos del siglo XX, hasta las más recientes del Catálogo de manuscritos de la Biblioteca Universitaria de Salamanca (Lilao-Castrillo 2002: II33-43), se han sucedido diferentes descripciones del códice. Algunas se limitan a un apunte de catalogación en repertorios bibliográficos de referencia, como la citada de Mussafia o las de Aubrun (I953), Simón Díaz (I963: I, nº 289I), Vàrvaro (I964), González Cuenca (I978) o Dutton (I982; I990-9I); otras se extienden algo más en la descripción, dependiendo del objetivo prioritario, aunque de ningún modo puedan considerarse exhaustivas: así ocurre con las de Moreno Hernández (ig87), Beltran (I999), BETA-Philobiblon (Manid ı22o, CNUM 26I) o Rodado Ruiz (2OOO, 2003, 20I6). . El listado anterior no es completo, pues cualquier estudio o edición de poemas contenidos en estos cancioneros suele acompañarse de una descripción de las fuentes manuscritas que los transmiten, cuya extensión y detalle varían considerablemente de unos trabajos a otros. En cualquier caso, entre las mencionadas hay que destacar, no solo por ser pionera sino también por su corrección, la de Aaron Wittstein de 19O7, que ha de ser el punto de partida para avanzar en el análisis del códice.

El volumen ha recibido diferentes denominaciones, aunque alguna ya resulta inexacta y ninguna es definitiva hasta la fecha:

7. Como ocurre en cualquier investigación abierta, el análisis que presentan estas páginas parte necesariamente de trabajos preparatorios previos, recoge los últimos avances y cierra y culmina el estudio material de SAıo: se modifican algunas hipótesis anteriores al hilo de hallazgos nuevos y se examinan múltiples aspectos de la materialidad del códice (un análisis paleográfico exhaustivo de ambos manuscritos, entre otros), así como de su proceso de elaboración y transmisión, no abordados en trabajos previos (Rodado Ruiz 2000, 2003, 20I6). Los resultados del estudio permiten presentar una visión integral del códice y formular una hipótesis acerca de la génesis y el proceso de copia y recepción de ambos cancioneros. 
I) Cancionero Antiguo: es el título que figura en el lomo.

2) Cancionero de Palacio: así se denominó en ocasiones durante el tiempo que el manuscrito permaneció en la Biblioteca de Palacio (Simón Díaz r963: I, nº 289i; BETA, Manid ı22O, CNUM 26I); «Wittstein lo llama, siguiendo a Adolf Mussafia, $X^{2}$, para distinguirlo de otros manuscritos del Palacio Real conocidos también como Cancioneros de Palacio y que llevaban la misma signatura» (Moreno Hernández I989: I9). Actualmente este título está en desuso ya que no se ajusta a la localización del códice y, además, coincide con la designación más común de $\mathrm{SA} 7$.

3) Cancionero del Colegio Mayor de Cuenca (Simón Díaz r963: I, nº 289I; Dutton r990-9I: 7, $625,626)$.

4) Cancionero compuesto de Salamanca: BETA (Manid $\left.{ }_{2} 220, \mathrm{CNUM}_{2} 6 \mathrm{I}\right)$.

5) SAıo: es la sigla que Dutton asignó a este manuscrito (เ990-9г: 7, 663; 4, 197) y se ha convertido en la denominación más común, debido a la generalización de su uso en ediciones y estudios especializados, muy probablemente, por carecer de un título más reconocible.

En el interior del códice se conservan las sucesivas signaturas anteriores: 353 (Colegio de Cuenca), VII D 4, II-F-5 y 593 (Madrid, Biblioteca de Palacio). La más antigua se encuentra en la segunda hoja de guarda, tras la de encuadernación, sobre la signatura actual (Ms. 2763); en la parte superior del primer folio donde se copia un índice incompleto del primer cancionero, una mano moderna en tinta negra y letra bastarda del siglo XVIII escribió el ex libris manuscrito del Colegio: «De la Bibliotheca del $\mathrm{Col}^{\circ}$. M ${ }^{\text {or }}$ de Cuenca», y sobre la palabra Bibliotheca aparece una cifra de seis números -IO32XX- los dos últimos mutilados en la encuadernación, como ha ocurrido también con algunas notas del margen derecho del segundo cancionero. Las signaturas de la Biblioteca de Palacio se encuentran en la contratapa donde puede leerse «de la Bibliotheca del Rey N. Señor», y a la vuelta de la primera hoja de guarda.

En la actualidad, el volumen se halla semidesencuadernado, con el lomo despegado. Sus medidas son 3О3Х2I8 mm. La cubierta es de pasta española, del siglo XIX (Lilao-Castrillo 2OO2: I4). Presenta color marrón verdoso, con cinco adornos y tejuelo con el título (Cancionero Antiguo) en el lomo. El papel de las guardas pegadas a las tapas es marmolado en marrón, azul y blanco, y se ajusta al estilo habitual -plegado español- en la encuadernación española.

Este códice facticio es un infolio en papel (29IX20 $5 \mathrm{~mm}$ ) formado por I 64 folios más las hojas

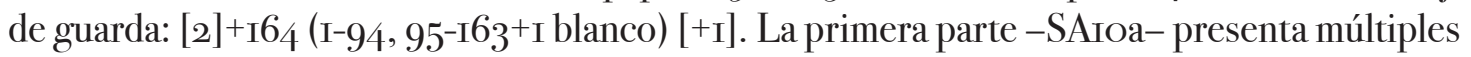
perforaciones que coinciden con el trazo de tinta; en muchos folios la tinta ha traspasado el papel por lo que se superponen las líneas del recto y vuelto y la lectura se hace muy difícil, además de otros desperfectos por polillas y manchas de humedad. Las roturas suelen coincidir con los calderones por la corrosión del ácido de la tinta acumulada, especialmente en los folios 4I, 44, 5I, 6I, 62, 63 y 67. Se han incorporado algunas hojas de papel de seda para separar y proteger los folios más deteriorados. En el segundo cancionero, algunas hojas están afectadas por manchas de humedad o de alguna sustancia que en algún momento dejó el papel oscurecido o que casi borró la tinta, lo que dificulta asimismo la lectura.

El manuscrito b que se dispuso junto al primero (a) debía de estar ya en ese momento muy deteriorado, seguramente con los cuadernos descosidos y en muchos lugares truncos, ya que se perdieron 65 folios, como puede deducirse del cotejo entre la numeración antigua y la moderna que se añadió una vez reencuadernado el códice, y que figuran en la esquina superior derecha de cada 
hoja a lo largo del manuscrito; es más, presumiblemente y como mínimo, serían 66 los perdidos, porque debemos contabilizar al menos uno más tras el f. II7 [ant. f. I34] en el que debía continuar la obra de Juan Agraz en diálogo con Marmolejo, como ya advirtió Wittstein (I9O7: 300), pues solo tres versos se recogen de esa pieza de Agraz en el último folio escrito del códice (f. II $7^{\text {bb }}$ ). Afortunadamente, la permanencia de la foliación previa a las pérdidas y al desorden de cuadernos permite reordenar el manuscrito y reconstruir la composición original del cancionero.

\section{I Marcas de agua y cuadernos}

Se detectan tres filigranas o marcas de agua. La primera corresponde a la primera hoja de guarda, y se corresponde con la figura $23^{8}$ recogida por Briquet: ${ }^{8}$ se trata de una luna en creciente sobre dos lunas nuevas, rematada por una corona de tres cruces. Este tipo y sus variantes se encuentran en piezas procedentes de la cancillería española escritas en Madrid o en Bruselas entre i6o 7 y I670 (Briquet I888: 83). En la luna intermedia aparecen dos letras, probablemente, las iniciales del papelero. Briquet ubica una filigrana muy similar en Bruselas hacia I598. ${ }^{9}$ Parece posible deducir que la hoja de guarda es papel más moderno, proveniente de una encuadernación anterior. Las otras dos marcas de agua reproducen un dibujo muy difundido: el gantelet o guante con los dedos más o menos separados e inicial o iniciales en la palma, rematado por una flor de cinco o seis puntas que sale del dedo corazón, filigrana presente en la mayor parte del cancionero. Varían las letras que figuran sobre el pulpejo del guante o mano: $M$ (I, 9I, 93-94, es decir, folios iniciales y finales del primer cancionero) o $M P(3,7-9$, II, I4-I6, 2I-23, 27, 29, 32, 34, 46, 48, 66, 88). La filigrana más parecida es la n⿳0 3 I9 de Briquet (I888: 93), fechada en I5O3-I5O4, pero su repertorio recoge marcas muy similares fechables en la última década del siglo XV. ${ }^{\text {IO }}$ También hallamos modelos semejantes en los primeros decenios del XVI, pues este tipo de guante «se rencontre souvent dans les lettres émanant de la chancellerie de Charles-Quint et datées de Tolède ou de Barcelone entre I534 et I54O» (Briquet I888: 93). " Además de las iniciales del guante, en esta figura puede variar la separación de los dedos, el puño y la forma de la flor o estrella. Esta puede ser más delgada, más puntiaguda o tener seis pétalos o puntas, características observables en el papel empleado en SAıob. Además, el puño no es estrecho y simple, como en SAıoa, sino ancho y rematado con doble línea, tipo manguito; la filigrana más parecida es la $n^{\circ} 3^{\text {II }}$ de Briquet, fechada entre I 490 y I $492 .{ }^{{ }^{I 2}}$

Así pues, el arco cronológico del papel que se empleó no contradice las fechas de escritura a las que remite el análisis paleográfico de ambos manuscritos, como se verá a continuación: últimos años del siglo XV y primeros decenios del XVI; aproximadamente, entre I49O y I54O.

El papel del primer manuscrito presenta 5 corondeles por folio de entre $35-40 \mathrm{~mm}$, sin rastros marcados de puntizones; y en la segunda parte del códice se advierten, asimismo, 5 corondeles por folio de medida similar, también sin marca de puntizones. La ausencia de reclamos y signaturas en todo el volumen, además del desorden en el segundo manuscrito debido a los errores del

8. Briquet 1888, 83 n $238:<$ https://archive.org/details/papiersetfiligroobriqgoog/page/n249/mode/2up $>$

9. Briquet 1984 [I9O7]: $2, \mathrm{n}^{\circ} 3246:\langle\underline{\text { https: / } / \text { go.uv.es/4Zs4CGul }}$.

Io. Briquet distingue cuatro tipos fundamentales de guante con flor. En este caso, la forma más cercana sería la del tipo $d$, que tiene una larga vida, pues permanece desde I440 a I598, vid. Briquet I888: 93, $\mathrm{n}^{\circ} 3 \mathrm{rg}:<$ https:/ /go.uv.es/ GyEMQz4>.

II. Existen tipos parecidos en Barcelona, Toledo y Valencia entre I5I9 y I536: véanse los nos IO 738 , IO 746 y IO $75^{8}$ de Briquet (1984 [1907]: 3, 553), filigranas similares a la de SAıoa: 〈https://go.uv.es/rzvLsBh〉, <https://go.uv.es/ $\underline{\mathrm{x} 7 \mathrm{cCb8v}}>\mathrm{y}<\underline{\mathrm{https}} / / / \mathrm{g}_{\mathrm{O}} . \mathrm{uv} \cdot \mathrm{es} / \mathrm{rNgEWQD}>$.

I2. Briquet I888: 282, $\mathrm{n}^{\circ}$ 3ІI: $\langle$ https://go.uv.es/IHr578n $>$. Casi idéntica es la no IO743 de Briquet I984 [1907]: 3 , $553:<$ https://go.uv.es $\left./ \mathrm{xXBO} \mathrm{L}_{5} \mathrm{LX}\right\rangle$. 
encuadernador, convierte el análisis de cuadernos en una tarea de muy difícil resolución. ${ }^{\mathrm{I3}}$ En SAıoa, las marcas del cosido permiten conjeturar que el grueso del manuscrito pueda estar formado por cuaternos (II, ff. I-88) con un terno final (ff. 89-94). SAıob parece iniciarse con dos quinternos -los que forman los ff. 95-II2, en donde acaba el Doctrinal de privados de Santillana- aunque con pérdidas en el primer cuaderno, pues, como he dicho antes, es muy probable que el manuscrito ya estuviera acéfalo cuando se encuadernó junto a SAsoa, ya que carece de índice, título, introducción o rúbrica general de primer autor -Santillana, en este caso-; solo consta la rúbrica específica para la Comedieta de Ponza, primera obra del manuscrito, sin más preámbulo.

Por otro lado, quedan huellas de folios arrancados (pequeños trocitos de papel pegados al pliegue central, por ejemplo, entre $\mathrm{I} 3 \mathrm{I}^{\mathrm{V}}-\mathrm{I} 32^{\mathrm{r}}$ y entre $\mathrm{I} 37^{\mathrm{v}}$ y $\mathrm{I} 3^{\mathrm{r}}$ ) y de pestañas de encuadernación; así, por ejemplo, al cuaderno al que pertenecían los ff. I32-I33 (ant. 2O-2I) le faltan 4 hojas (entre el I33 y I35 [2I-26] $)^{\mathrm{I}}$; entre los folios I32-I33, queda la pestaña de insertar en la encuadernación un folio suelto y descolocado, el I34. El conjunto forma 7 folios, pero se aprecia un resto de pestaña -no completa, solo hasta mitad de folio- entre I33 y I34, quizá para insertar el fol. I35, que habría quedado suelto y formaba parte del cuaterno. Parece que el encuadernador intentó recomponer los folios sueltos y dispersos de algunos cuadernos y, con más errores que aciertos, consiguió convertir la secuencia del cancionero en un galimatías. Es probable que en su disposición original el segundo manuscrito estuviera formado por los dos quinternos iniciales mencionados, seguidos de cuaternos, el tipo más frecuente de cuaderno en manuscritos medievales (Sánchez-Prieto y Martínez Dávila 20I5: 4.I): serían I 4 o I5, dependiendo del número de folios finales perdidos. Sin embargo, el estado actual de este cancionero ofrece escasos indicios para la conjetura: ciertamente, es muy arriesgado pronunciarse sobre la tipología original de cuadernos desmembrados y desplazados.

\subsection{Impaginación y análisis paleográfico}

\subsection{SAiOa}

La mayor parte presenta dos columnas con texto regular respecto a la caja de escritura, cuya dimensión total es de $150 x 220$ mm. En el índice es mayor, ya que en los puntos extremos mide I $95^{X 295} \mathrm{~mm}$ y ocupa casi la totalidad del folio, pues parece haberse realizado con descuido e intentando aprovechar al máximo el espacio; además, apenas queda margen superior e inferior, bien por ese prurito de aprovechamiento, bien debido a algún corte de encuadernación. En las obras en prosa y en algunas composiciones en arte mayor aumenta el tamaño de la caja de escritura a I6ox230

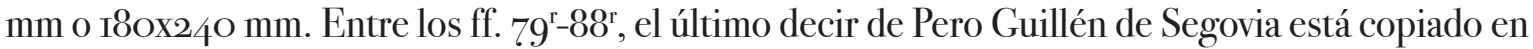
el centro de la plana en columna única de I2OX220 $\mathrm{mm}$. Este caso excepcional es determinante para establecer las fases de copia del manuscrito, como se verá después. Tras esta pieza, las últimas obras del cancionero recuperan la impaginación en doble columna y presentan caja de escritura variable aproximada a I6ox26o mm: se trata de un decir de Estúñiga, I7 obras en versión única de Hernando Colón y cuatro piezas anónimas de cierre. Es importante tener presente que la participación de varias manos y la intermitencia de la copia repercute de manera decisiva en la configuración gráfica del manuscrito.

I3. Así lo reconocen también los autores del Catálogo de manuscritos de la Biblioteca Universitaria de Salamanca: «cuad. de difícil determinación» (Lilao-Castrillo 2002: п133).

I4. Es errónea la indicación del ms. en I33 ${ }^{v}$ en donde una nota de mano moderna dice que faltan 4 hojas entre 133 y I34. En realidad, el fol. I34 (I9 antiguo) es anterior al I32 (2O antiguo) y figura descolocado en el códice. 
Por término medio, el número de líneas por columna oscila entre 27 y 29 en las obras en verso, y 30-34 en las introducciones en prosa, con menor espacio de separación entre líneas; la columna puede variar hasta en cinco líneas y suele depender del usus scribendi del copista encargado. En algunos folios no coincide el pautado de ambas columnas y, en esos casos, una de ellas presenta su caja de escritura ligeramente inclinada, como ocurre en los ff. $5^{\mathrm{r}}$ y I $3^{\mathrm{r}}$, por ejemplo. No hay regularidad, tampoco, en el número de estrofas por columna.

Se utiliza tinta negra en rúbricas y textos, aunque, como suele ser habitual cuando la copia se realiza en distintos tiempos, se advierten varios tonos -del negro al sepia- relacionados probablemente con la composición de la tinta; además, en algunos lugares los folios presentan un aspecto limpio y sin rastro de manchas, mientras que en otros -con tendencia al sepia- el efecto corrosivo del ácido de la tinta ferrogálica mancha, a manera de fondo, secciones de la caja de escritura llegando a hacer el texto ilegible en mucho lugares.

En esta primera parte del códice en la que intervienen varios copistas, como ya he dicho, encontramos letras góticas cortesanas, humanísticas e híbridas (es decir, con soluciones formales y cursivas). ${ }^{15}$ Este manuscrito constituye una muestra perfecta de la transición caligráfica en Castilla durante el primer tercio del siglo Xvı y las constantes oscilaciones entre el uso de la gótica cursiva cortesana y la humanística, con un notable repertorio de variedades híbridas. Tras el examen del manuscrito, el dictamen inicial es que se copió de forma descuidada y en colaboración asistemática: en muchas obras se advierte más de una mano -son representativos los ff. $2^{\mathrm{v}}, 28^{\mathrm{v}} \mathrm{o} 33^{\mathrm{va}}-\mathrm{y}$ en general, en todo el cancionero, se observan constantes variaciones de ejecución gráfica, pues el trazado adquiere, según el copista, trazos más angulosos o redondos, más limpios o, por el contrario, más abigarrados, con astiles y caídos más o menos prolongados en algunas letras. En líneas generales, la misma mano que copia los textos suele ser responsable de las rúbricas, pero hay excepciones. Pueden distinguirse las siguientes manos:

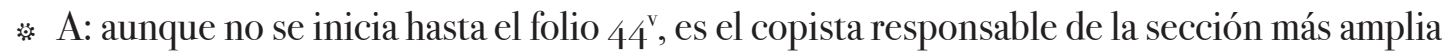
del cancionero (ff. $44^{\mathrm{v}}-7 \mathrm{O}^{\mathrm{r}} / / 73^{\mathrm{r}}-88^{\mathrm{v}}$ ). Se advierten rasgos similares a los de las manos C y D (letra gótico-humanística), pero también diferencias, como los caídos de $y / g / \gamma /$, y muchos más adornos en los astiles de la $v$ y en la $a$ final de verso, propios de la gótica cursiva cortesana.

* B: es el responsable de la copia del extenso Triunfo del Marqués, de Diego de Burgos, dedicado a la muerte del Marqués de Santillana (ff. $\left.28^{\mathrm{v}}-44^{\mathrm{r}}\right)$; intervienen también las manos I ( $\left.28^{\mathrm{va}} / / 33^{\mathrm{va}}\right)$ y C (f. 28 r). Comienza el copista con letra gótico-humanística, cuidada y con impaginación limpia, pero evoluciona hacia una escritura más cursiva, abigarrada en muchos folios y con numerosas tachaduras y enmiendas, quizá debidas a la dificultad de la copia por tratarse de una pieza con abundante nomenclatura grecolatina.

C: ff. $13^{\mathrm{r}}-28^{\mathrm{r}}$, letra humanística con rasgos de cortesana, por ejemplo, en las abreviaturas que se emplean; en algunos folios cambia el tamaño y el trazo. Es similar a D, pero hay suficientes rasgos claramente distintos que aconsejan considerarla otra mano.

D: letra gótico-humanística cuidada (ff. $\left.2^{\mathrm{r}}-4^{\mathrm{v}} / / 9^{\mathrm{r}}-\mathrm{I} 2^{\mathrm{v}}\right)$. Es el amanuense que inicia la copia, aunque su tarea queda interrumpida por la intervención de $\mathrm{F}$ en ff. $5^{\mathrm{r}}-7^{\mathrm{v}}$ y $8^{\mathrm{v}}$.

E: copia las obras de Hernando Colón $\left(88^{\mathrm{vb}}-92^{\mathrm{r}}\right)$. De nuevo, una letra humanística con algunas soluciones gráficas góticas; es mano muy similar a F, una gótico-humanística: por ejemplo, el

I5. Quede aquí constancia de mi agradecimiento al profesor Mauricio Herrero, que tuvo la gentileza de aclarar mis dudas acerca de algunas peculiaridades gráficas de este códice. 
trazo de la p es idéntico y muy significativo porque solo aparece en E, F y H, si bien difiere en algunos rasgos como en ciertas realizaciones de la r doble inicial (no en todas); de ahí que deba considerarse mano distinta.

F: parece ocuparse únicamente de la segunda mitad del primer cuaderno (ff. 5-8), a excepción de la plana del f. $8^{\mathrm{r}}$ en que interviene la mano I; es letra gótico-humanística cuidada, con tendencia a la cursividad $\left(5^{\mathrm{r}}-7^{\mathrm{v}} / / 8^{\mathrm{v}}\right)$.

* G: copia las cuatro últimas obras del cancionero en los folios finales $\left(92^{\mathrm{r}}-94^{\mathrm{v}}\right)$. Escribe con letra humanística en la que permanecen abundantes nexos y abreviaturas típicamente cortesanas, y remite a una cronología algo posterior al resto del manuscrito.

H: Mano con letra gótica cursiva cortesana, para terminar de copiar el Juego de naipes, de Fernando de la Torre, y varias obras más hasta la pieza de Juan de Torres $\left(7 \mathrm{O}^{\mathrm{v}}-73^{\mathrm{r}}\right)$.

I: interviene esporádicamente, con letra humanística muy claramente delimitada a lo largo del cancionero; estrofas $2-3(+4 \mathrm{Vv}$. de la 4$)$ en $2^{\mathrm{va}} / / 8^{\mathrm{r}} / / 28^{\mathrm{va}} / / 33^{\mathrm{va}} /$ rúbricas en $5^{\mathrm{vb}}$ y $24^{\mathrm{rb}}$.

J: es el responsable del índice incompleto del cancionero que figura en el f.I ${ }^{\mathrm{r}}$, con letra gótica cursiva cortesana.

* Copista corrector Z: podría ser el responsable de las detalladas manículas y enmiendas en grafemas y versos sobreescritos o añadidos (ff. $2^{\text {rb }}, 3^{\text {ra }}, \mathrm{I}^{\mathrm{rb}}, 6 \mathrm{O}^{\mathrm{rb}}, 66^{\mathrm{r}}, 66^{\mathrm{v}}, 88^{\mathrm{vb}}$ ). Parece ser una mano correctora contemporánea: así puede observarse en f. $66^{\mathrm{r}}$, margen inferior izquierdo, y f. $66^{v}$, tachadura y corrección al final de la primera columna de texto; cabe suponer que el mismo lector/corrector, pues el tono de la tinta es similar, añade un verso que faltaba, concretamente el quinto de la tercera estrofa en $3^{\text {ra }}$, y quizá también escribió el nombre de don Hernando Colón en la rúbrica del f. $88^{\text {vb }}$. Asimismo, aparecen algunos dibujos y adornos: una manícula con el índice anormalmente alargado señala el primer verso de la tercera estrofa en $2^{\text {bb }}$ otra mano de las mismas características que la anterior señala la composición de Gómez Manrique a la muerte del Marqués de Santillana en $\mathrm{I}^{\mathrm{rb}}{ }^{\mathrm{r}}$; otros dos adornos se observan en ff. $60^{\mathrm{r}}$ y $66^{\mathrm{v}}$; y, por último, dos firmas aparecen en los folios $\mathrm{I}^{\mathrm{r}}$ y I $63^{\mathrm{v}}$, con la misma tinta que la indicación sobre la procedencia del códice del margen superior del primer folio, pues se deben al comisario y al escribano que debían rubricar la primera y la última hoja escritas de cada manuscrito, según ordenaba la Real Cédula para la inspección de las bibliotecas de los colegios mayores salmantinos, como ya hemos visto (Mestre Sanchis et al. ed. 2002: 69-75).

Finalmente, en la esquina superior derecha de los folios una mano moderna se encarga de numerar el manuscrito en arábigos sobre la numeración romana original, y corrige algunos errores a partir del folio XVI.

\subsubsection{SAiob}

El segundo manuscrito está escrito a dos columnas, con una dimensión de I65x225 mm y texto habitualmente regular respecto a la caja de escritura. En bastantes folios es muy evidente el pautado de ambas columnas, que encuadra la caja de escritura: $99^{\mathrm{r}}, \operatorname{IO}^{\mathrm{v}}, \mathrm{IO}^{\mathrm{V}}, \mathrm{IO}^{\mathrm{r}}, \mathrm{IO}^{\mathrm{r}}, \mathrm{III}^{\mathrm{r}}, \mathrm{II}^{\mathrm{r}}$, I $27^{\mathrm{r}}$, también en algunos folios finales como en $\mathrm{I} 58^{\mathrm{r}}$. A veces, el pautado ha traspasado el folio produciendo roturas, sobre todo en el lateral interno cercano al lomo (en f. ıı,, por ejemplo), tal vez por haber sido preparado a punta seca, pues este sistema es recuperado a partir del siglo XV por algunos humanistas, que se esfuerzan en imitar la estética codicológica carolingia (Rodríguez Díaz 2004: 553; Sánchez-Prieto - Martínez Dávila 2OI5: 5·9). No obstante, también es posible que usaran otro sistema de pautado -con tablillas, quizá- y que el exceso de presión sobre el papel acabara 
rompiéndolo. A veces la línea de escritura sobrepasa el pautado horizontal superior, como ocurre en el f. I22 $^{\mathrm{v}}$, que presenta un margen frontal anormalmente amplio; se trata, sin duda, de un error detectado por el copista y que le llevó, seguramente, a no respetar los límites del pautado.

Como ocurre en el primer cancionero, no existe regularidad en el número de estrofas por columna, algo esperable en un manuscrito en el que igualmente han intervenido muchas manos y fue copiado en varias fases; es difícil, si no imposible, mantener cierta uniformidad de copia en esas circunstancias. Solo en una ocasión se deja en blanco parte de un folio: ocurre en $\mathrm{I} 32^{\mathrm{rb}}$ y la mitad superior de $132^{\text {va }}$, en lo que parece ser un intento de dejar el espacio suficiente para copiar posteriormente una o varias respuestas tras la pregunta de Santillana que figura allí (IDo3O2, SAıob-92), obras que en ese momento no se tendrían a mano.

También coinciden las dos partes del códice en la variedad de tonos de la tinta -del negro al sepia- relacionados, como ya hemos dicho, con la composición de la propia tinta, pues en algunos lugares los folios presentan un aspecto limpio y en otros, muy manchado, casi en la totalidad de la caja de escritura. En algunos folios, en cambio, el tono es muy claro y casi ilegible, a causa de la humedad y otros accidentes.

Un aspecto muy complejo en este cancionero -también en SAıoa, como se ha visto- es el estudio de las numerosas manos que intervienen en el proceso de escritura; la génesis y copia del repertorio parece haber sido desigual, en desarrollo casi abrupto, probablemente por acumulación y con añadidos no proyectados. Incluso se da el caso de piezas de un autor -algunas obras de Santillana, por ejemplo- que lógicamente tendrían que haber sido copiadas sin largas pausas o demoras, en las que intervienen varias manos, aun en el mismo folio.

En líneas generales, alternan dos tendencias en la escritura: una letra gótico-humanística, con más o menos rasgos de cursividad, junto a una humanística de trazo más definido que, no obstante, mantiene soluciones gráficas propias de la letra cortesana (se advierte, por ejemplo, en el trazo de la $s$ alta, la lo el nexo tr, especialmente en el grupo str, pero también en la prolongación de la $f$ o la $h$ envolviendo la propia letra o la anterior). De ahí que permanezca, por ejemplo, la $d$ uncial, sola o alternando con la de astil recto. En la segunda parte del cancionero, podríamos calificar de humanística plena la letra de algunas rúbricas y unos pocos textos. Además, como es esperable, se observan variaciones en la ejecución en cualquiera de los tipos mencionados. Esta tipología escritural remite a una cronología compatible con los primeros decenios del siglo XVI.

Las rúbricas se escriben en tinta negra y, en muchos casos, de la misma mano que copia los textos, sobre todo en la primera mitad del manuscrito -me refiero a la primera mitad reordenada, es decir, al cancionero según su secuencia original- pues a partir del f. ı42, por ejemplo, hay un bloque con rúbricas de otra mano. Asimismo, solo una sección en la parte final del cancionero presenta calderones en el comienzo de estrofa.

El examen del manuscrito me lleva a distinguir las siguientes manos:

A: ff. IO $4^{\text {rb }}-\mathrm{IIO}^{\mathrm{rb}}, \mathrm{I} 34^{\mathrm{ra}}, \mathrm{I} 34^{\mathrm{rb}}[$ pieza final $], \mathrm{I} 32^{\mathrm{r}}-\mathrm{I} 33^{\mathrm{v}}, \mathrm{I} 35^{\mathrm{r}}, \mathrm{I} 35^{\mathrm{rb}}-\mathrm{I} 38^{\mathrm{va}}, \mathrm{I} 42^{\mathrm{r}-\mathrm{va}}, \mathrm{I} 4 \mathrm{O}^{\mathrm{I}} \mathrm{I} 5 \mathrm{O}^{\mathrm{rb}}, \mathrm{II} \mathrm{8}^{\mathrm{r}}, \mathrm{I} 27^{\mathrm{rv}}$. Es la letra humanística predominante, y diferente a E -con la que da comienzo el manuscritoen algunas soluciones gráficas, más cortesanas en esta que en aquella; asimismo, el ductus, el ángulo o el peso de las letras varían, pues el trazo de este copista es menos lineal y cuidado, al tiempo que cambia la mise en page al ser mayoritariamente arte menor (frente a E, arte mayor), lo que se traduce en un espaciado entre versos también mayor que repercute en el tamaño de las letras. En algunos folios, la escritura es algo más cursiva que en otros.

B: ff. I $43^{\mathrm{r}-\mathrm{va}}, \mathrm{I} 44^{\mathrm{ra}}-\mathrm{I} 46^{\mathrm{v}}, \mathrm{I} 47^{\text {vb }}, \mathrm{I} 5 \mathrm{O}^{\text {vb }}-\mathrm{I} 52^{\text {va }}, \mathrm{I} 52^{2^{\text {vb }}-\mathrm{I}} 56^{\text {va }}, \mathrm{I} 62^{\text {va }}$. Es letra gótica cursiva cortesana, con bastantes similitudes con J. 


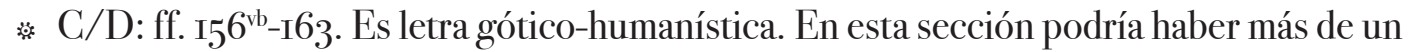
copista: una mano con tendencia humanística y otra, más cortesana, que podría ser la misma

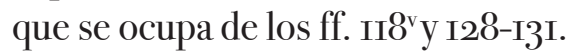

E: ff. $95^{\mathrm{r}}-99^{\mathrm{va}}, \mathrm{IOO}^{\mathrm{r}}-\mathrm{IO}^{\mathrm{v}}, \mathrm{I}^{3} 4^{\mathrm{rb}}-\mathrm{I} 34^{\mathrm{vb}}$. Es el copista encargado de las primeras piezas del cancionero. Letra humanística de impaginación regular y cuidada, similar a A, pero con diferencias en el trazo de algunos grafemas.

* F: ff. II ${ }^{\mathrm{r}}$-I26 ${ }^{\mathrm{v}}$. En esta sección hay letra humanística con algunas soluciones gráficas góticas.

G: ff. I39 ${ }^{\text {va }}-\mathrm{I} 4 \mathrm{I}^{\mathrm{v}}, \mathrm{I} 48-\mathrm{I} 5 \mathrm{O}^{\text {vb }}$. Es letra humanística con algún rasgo gótico, muy similar a Ay E, pero la $d$ predominante no es uncial y presenta astiles rectos en $b$ y $l$.

H: ff. II $3^{\mathrm{r}}-\mathrm{II} 7^{\mathrm{v}}$. Este copista se ocupa de una sección breve, cinco folios en escritura gótica cursiva cortesana.

I: ff. $\mathrm{IO}_{3}^{\mathrm{vb}}-\mathrm{IO}_{4}^{\mathrm{rb}}, \mathrm{IIO}^{\mathrm{vb}}-\mathrm{II} 2^{\mathrm{v}}$. Letra gótico-humanística, aunque diferente a M -segundo tipo escritural que aparece en el cancionero- por algunos rasgos, especialmente, la $s$ en espiral que no aparece aquí y sí en M.

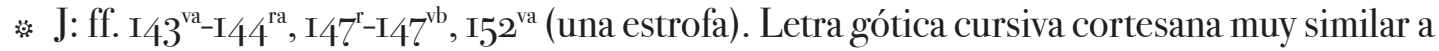
$\mathrm{B}$, aunque el trazo es claramente diferente: más grueso y con grafías góticas cortesanas muy abiertas, casi de tipo procesal en algunos casos.

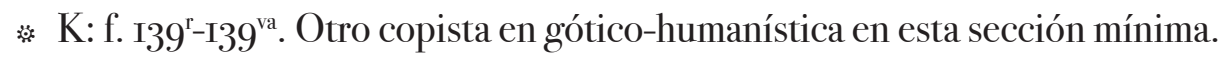

L: ff. $\mathrm{I} 35^{\mathrm{va}}, \mathrm{I}_{3} 8^{\mathrm{va-b}}, \mathrm{I} 42^{\mathrm{vb}}$. Es letra gótica cursiva cortesana.

M: f. $99^{\text {va-vb }}$. Letra gótico-humanística y desarrollo breve como K.

A estas manos es preciso añadir la mano o manos correctoras -posiblemente, dos- responsables de múltiples aclaraciones y enmiendas en el cancionero. ${ }^{16}$ Una de las más interesantes afecta a una obra de Santillana que se copia dos veces en SAıob (IDI767, «Gentil dueña tal pareçe») ${ }^{\text {rz }}$-en los ff.

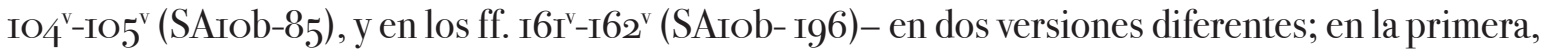
el decir presenta Io estrofas (en otros testimonios son 8, como en SAıob-I96), la última de las cuales está precedida por la indicación «fin» en el f. $\mathrm{IO}_{5}^{\mathrm{v}}$. El error se produce porque a continuación encontramos el anuncio de otra finida y la propia estrofilla de cuatro versos, ambos tachados; parece que el copista advirtió el fallo, tachó todo y copió la estrofilla donde correspondía, en el margen derecho del f. IO $^{\mathrm{r}}$, entre las estrofas viii y ix, donde figuran los versos que había tachado: «coraçon a dios te do / ca donde mora pesar / no puedo mucho tardar / pues que su contrario so». Esta disposición de la finida a manera de estribillo, precediendo a las dos estrofas finales del decir -que son las añadidas en SAıob-85- aisla la parte final y conforma una canción como cierre del poema. El decir seguido de la canción también figura en los cancioneros TPI e YB2, que recogen obras de Santillana. En cambio, la segunda versión que se copia en SAıob prescinde de la canción adicionada, y solo presenta el estribillo, de nuevo como finida. Justo debajo de la rúbrica el corrector ha advertido: «esta esta otra vez escrita a cartas onze» (f. II de la numeración antigua). ${ }^{18}$

I6. También figuran unas notas modernas a lápiz - ¿quizá de Wittstein?-aludiendo a la edición de Santillana que hiciera Amador de los Ríos (1852).

I7. Es una obra de la que se conservan 9 testimonios con variantes de entidad y diferencias en el número de estrofas y secuenciación. Puede leerse el poema y sus problemas ecdóticos en las cuidadas ediciones de Pérez Priego (I983: II8I22) y Rohland de Langbehn (I997: 64-66, 263).

I8. La misma indicación aparece por error, y tachada, bajo la rúbrica de la composición anterior de Santillana, el decir 
Otra enmienda aparece en la esquina inferior izquierda del f. $\mathrm{IO}^{\mathrm{ra}}{ }^{\text {: }}$ un recuadro con dos señales contiene 8 vv. que han de insertarse tras la primera estrofa de la primera columna, donde constan las mismas llamadas. Y algo similar ocurre con otra inserción de estrofa en el f. I63v , en el Sueño de Santillana. Más enmiendas con palabras interlineadas, correcciones en los márgenes o glosas figuran en otros lugares: ff. II $6^{\mathrm{v}}$, II $8^{\mathrm{v}}, \mathrm{II} 9^{\mathrm{v}}, \mathrm{I}_{2} \mathrm{O}^{\mathrm{r}-\mathrm{v}}, \mathrm{I}^{\mathrm{r}} \mathrm{I}^{\mathrm{r}-\mathrm{v}}, \mathrm{I} 28^{\mathrm{r}-\mathrm{v}}, \mathrm{I} 29^{\mathrm{r}}, \mathrm{I} 3 \mathrm{I}^{\mathrm{r}}, \mathrm{I} 35^{\mathrm{r}}, \mathrm{I} 5^{8^{\mathrm{v}}}, \mathrm{I} 6 \mathrm{O}^{\mathrm{v}}, \mathrm{I} 6 \mathrm{I}^{\mathrm{v}}, \mathrm{I} 62^{\mathrm{v}} \mathrm{y}$ I6 $33^{\mathrm{r}}$.

Muchas de estas enmiendas se encuentran en las obras de la segunda sección dedicada a Santillana, en las que una mano correctora de la misma época ha cotejado los textos con uno de los manuscritos que transmitieron la obra del marqués, y ha ido anotando correcciones o variantes. Así, en los dos últimos folios del actual cancionero, donde se copia el Sueño de Santillana, que queda interrumpido en I63v, el lector-corrector coteja las lecturas de varios versos y anota las variantes donde corresponde. Es interesante la enmienda en el último verso del f. I6 $3^{\text {rb }}$ : en el margen derecho se apunta un verso que falta («en troncos fieros nudosos» v. 92) antes del último copiado («los cantos melodiosos»); para resolver la falta en la estrofa, la versión de SAıob añadió otro verso que no figura en otros testimonios («y los deleytes gozosos»), pero lo más valioso no solo es esta variante, sino la indicación de la fuente que autoriza las enmiendas, que se anota justo encima del verso restaurado y dice: «del Ms del M.». Así deja constancia el corrector de que trabaja con fuente fidedigna.

Por último, conviene recordar que SAıob es un manuscrito estragado y trunco, que ha sufrido el celo moralista de lectores o censores. Muchos de los folios que faltan contenían obras que fueron censuradas; afortunadamente, algunas estrofas de esas obras se salvaron por figurar antes o después de otras piezas que sí interesaba conservar, y tan solo presentan tachaduras ligeras que no impiden la lectura.

\section{Constitución interna, génesis y cronología}

\section{I SA10a}

SAioa recoge 76 composiciones de diversos autores en lengua castellana, a excepción de una pieza francoitaliana situada en los folios finales (IDi763, SAıoa-74, 93 ${ }^{\mathrm{v}}-94^{\mathrm{r}}$ ). ${ }^{{ }^{9}}$ Integran el cancionero dos núcleos principales: 28 obras de Pero Guillén de Segovia, distribuidas a lo largo del repertorio, y ${ }_{7}$ de Hernando Colón, que ocupan los últimos folios junto a otras 4 piezas anónimas. ${ }^{20}$ Estas obras finales -excepto una- y I 4 poemas de Guillén han llegado exclusivamente a través de este cancionero, además de los 7 Salmos de Diego de Valera, sendas obras de Juan Agraz y Juan de Torres, 3 de Juan de Viana, 3 de Alonso de Lira y 2 introducciones en prosa; es decir, un total de $5^{\mathrm{I}}$ unica, un número considerable en relación con el conjunto del manuscrito.

El cancionero se abre con los Salmos penitenciales de Diego de Valera, a los que siguen obras de Gómez Manrique, Pero Guillén, Diego de Burgos, Lope de Estúñiga, Juan de Viana, Fernando

«Non es umana la lunbre» (IDo29o, SAıob-I95). Como se puede ver, también el corrector cometió errores.

19. Dutton numera 75 obras debido a que ha contabilizado como una sola pieza el Juego de naipes, de Fernando de la Torre, y el prólogo que lo precede (ID 593 P 594 / ID594, SAıo-39P / SAıoa-39, r990-9i: 4, 2 I6-220). No sigue el mismo criterio en los demás prólogos o introducciones en prosa (SAioa-II, SAioa-I4, SAioa-i6, SAioa-48).

20. Aunque ninguna de las rúbricas indica nombre de autor, la primera de ellas (IDI76I) es obra de Bartolomé de Torres Naharro (Rodado Ruiz en prensa b). 
de la Torre, Juan de Mena -sin rúbrica de autor-, Alonso de Lira, Juan Agraz, Juan de Torres, Villasandino y Lope de Estúñiga. Las obras de Pero Guillén articulan el cancionero y le sirven de eje, pues algunas de ellas son respuestas a obras de otros poetas o bien tienen relación temática, y, por ello, se disponen seguidas o muy próximas. Así ocurre con las piezas seleccionadas de Gómez Manrique, Valera o Lope de Estúñiga, al menos la primera de las dos que se incluyen de este último. Este parece ser el criterio rector del compilador: sobre la base de un repertorio de Pero Guillén, se han seleccionado una serie de obras en diálogo con las del poeta sevillano, aunque no todo el cancionero responde a ese sistema. Las dos secciones finales -poemas de Colón y las cuatro últimas obras- escapan a ese criterio.

En el f. Ir figura un índice incompleto del cancionero, escrito por un copista que no interviene en el resto del manuscrito, datos para tener en cuenta en el análisis del proceso de elaboración. ${ }^{2 \pi}$ Faltan en esa tabla las dos obras de Lope de Estúñiga y la respuesta de Pero Guillén a la primera de ellas, el Combate de amor -atribuido aquí al poeta sevillano-, una canción anónima, la sección de obras de Hernando Colón y las cuatro piezas finales.

Las inserciones en el interior del cancionero figuran justo antes y después de la microsección de Viana: antes aparece la primera pieza de Estúñiga y la respuesta de Guillén, y tras las canciones de Viana, el Combate de amor. Cabe la posibilidad de que el copista encargado del índice se despistara y dejara de anotar algunos títulos, o bien que la tabla responda a una compilación distinta a SAıoa y sea el índice de un cancionero que se copia y al que se le añaden otras piezas en el interior y al final, hipótesis bastante más probable. Bien es verdad que las indicaciones de folio en el índice se corresponden exactamente con el lugar que ocupan las obras copiadas, es decir, que las piezas añadidas no han alterado el lugar que se indica para las obras que siguen a continuación; y, por otra parte, no cabe pensar que se aprovecharan espacios en blanco del manuscrito para insertar esas obras añadidas, porque la primera canción de Viana se copia al final de la primera columna del f. $66^{v}$, y la rúbrica del Juego de naipes figura al final del f. $67^{r}$, ubicaciones extrañas para iniciar sección u obra tras un espacio presuntamente reservado para otras piezas. Todo ello permite inferir que el índice fue copiado del cancionero que sirvió de modelo, pero el copista se encargó de comprobar y anotar el número del folio en el que figuraba cada pieza de ese índice en el nuevo manuscrito, aunque se despreocupó de las piezas añadidas; y no fue por problemas de espacio, pues sobra hueco al final de la segunda columna de la tabla y el vuelto está en blanco, lo que indica que este índice evidencia solo una de las fases de compilación y copia de SAıoa. La canción anónima agregada en el f. $78^{v}$ tras la obra de Villasandino sí se copia para rellenar un hueco sobrante, ya que se ha ajustado el tamaño de la letra y, además, cambia la mise en page en el folio siguiente: la obra de Guillén que comienza allí se copia en una sola columna que abarca toda la caja de escritura (Rodado Ruiz 2or7a: 276-77; 2OI7b: 22I-22). Tras esta pieza del sevillano se copia el otro decir de Estúñiga que tampoco figura en la tabla inicial y, a continuación, las obras de Colón y las piezas finales.

Otro detalle significativo en relación con las fases de compilación se encuentra en una variante que introduce el índice respecto a la rúbrica del texto correspondiente en el cancionero. Se trata del decir de Pero Guillén dirigido al rey (IDI726): el índice especifica «al rey don Hernando luego que reinó», mientras que la rúbrica dice «al rey nuestro señor luego que reinó e fizo pazes con Aragón e Navarra», y en el v. I 4 se menciona al «rey don Enrique». Rúbrica y mención revelan el error del índice y permiten fechar el texto en los primeros años del reinado de Enrique IV y, en todo caso, en I 454 como fecha post quem. Así pues, el copista del índice no leyó el texto del poema porque se habría percatado del error (ya hemos dicho que la mano del índice no interviene en la copia del

2I. Las indicaciones de folio en el índice remiten a la foliación antigua del manuscrito en números romanos, que se inicia con el $i$ en el moderno f. 2. 
manuscrito); seguramente, él está copiando el índice de otro cancionero que ha servido de modelo, y en esa entrada añade, tras la palabra 'rey', el nombre del monarca de su tiempo -Fernando el Católico- que es el rey que él tiene presente.

Todo parece indicar que SAıoa es copia de otro cancionero al que se han añadido obras seleccionadas. Moreno Hernández (I989: 20) propuso que podía tratarse de una recopilación hecha en la década de los sesenta por Pero Guillén de Segovia, el autor mejor representado en esta colectánea. Las peculiaridades de los textos seleccionados, muchos de ellos acompañados por introducciones o respuestas de Guillén, así como la cuidada disposición de piezas semejantes -como los plantos de Gómez Manrique y Diego de Burgos sobre la muerte de Santillana, o las dos series de salmos penitenciales, en las que contrasta el contrafactum de Valera con el texto religioso de Guillén- confirmarían la hipótesis de Guillén como compilador, pues fue hombre muy culto, escribano de oficio y contador mayor del arzobispo de Toledo, Alfonso Carrillo; sin embargo, los abundantes errores de copia o la intervención de muchas manos en el manuscrito no se avienen con dicha hipótesis. Además, las obras finales del cancionero no pueden pertenecer a la presunta recopilación inicial de Guillén puesto que se fechan en el siglo XVI.

Para enredar aún más los problemas de génesis y transmisión, en la magnífica biblioteca de Hernando Colón en Sevilla hubo un cancionero que contenía obras de autores coincidentes en número y secuencia con buena parte de SAioa; ${ }^{22}$ reunía, por este orden, obras de Diego de Valera, Gómez Manrique, Pero Guillén, Diego de Burgos, Fernando de la Torre y Hernando Colón.

Con estas premisas, los indicios hallados hasta el momento conducen a la siguiente hipótesis de transmisión: ${ }^{23}$ Pero Guillén de Segovia pudo ser el autor-compilador de un cancionero personal, hoy perdido, que he llamado A*, compilación que se cerraría con los Metros de los doce estados, la pieza copiada en columna única que resulta adecuada a la destacada posición de cierre del cancionero, por su disposición y contenido. El cancionero perdido de la Biblioteca Colombina -al que he denominado $\mathrm{B}$ - pudo ser una copia del primer repertorio de Guillén $\left(\mathrm{A}^{*}\right)$ en la que se añadieron los poemas de Colón o, incluso, pudo ser el propio cancionero de Guillén adquirido, quizá, por el insigne bibliófilo, en cuyos folios finales se copiaron sus obras.

Aquel cancionero personal de Guillén podría haber sido también el modelo de C, que es el repertorio indexado en la tabla inicial de SAıoa, posterior a I474, cuando Fernando el Católico se convirtió en rey de Castilla por matrimonio: ahí fueron añadidas varias piezas de Guillén, además de las obras de otros poetas (Viana, Lira, Torres, Agraz) que cambian de orientación la temática del original y la inclinan hacia temas amatorios y cortesanos. A partir de este cancionero $\mathrm{C}$, como modelo, un nuevo lector-propietario encarga o prepara una copia en la que se añaden otras piezas que, en conjunto, conforman SAioa: las obras de Estúñiga, con la respuesta de Guillén a la primera de ellas, el Combate de amor y la canción anónima; permanece el interés por reunir obras de Guillén y por insistir en la temática cortesana. Finalmente, en las hojas finales de este cancionero, en fecha cercana a juzgar por la semejanza y proximidad cronológica de la letra en las distintas secciones del manuscrito, se copian los poemas de Hernando Colón y, como último estadio, las cuatro obras finales.

En este punto se agotan los datos para explicar cómo llegan a SAıoa las obras de Colón, es decir, si existió contaminación entre A* / (que contenía sus poemas) y C (que contenía muchas más obras que $\mathrm{A}^{*} / \mathrm{B}$, que hoy forman parte de SAioa); o, por el contrario, si la sección de Colón procede de otra fuente. Desconocemos el grado de difusión y transmisión de la obra poética hernandina, que

22. Se trata de un cancionero hoy perdido, que figura en los repertorios colombinos con los asientos $2054 \mathrm{R}$

(Registrum B), 3583M (Materias), 2995E (Epitomes) y con varias entradas por autores en el libro de Proposiciones.

23. Resumo aquí algunas conclusiones parciales de un trabajo de reciente aparición (Rodado Ruiz 2O2O). 
tampoco es muy extensa; cierto es que el explicit de B -consignado en el Registrum de su bibliotecano se corresponde con ninguna pieza poética conservada. Tal vez fuera el explicit de una obra de Colón que cerraba el cancionero B (o el A*, si se trataba del mismo códice), pero que no llegó a SAioa.

Sin abandonar el ámbito de la conjetura, a partir de los indicios apuntados, quizá el compiladorpropietario de SAioa perteneciera al entorno de Colón, estuviera interesado -como el propio don Hernando- en la poesía de Guillén, y añadiera al final algunas piezas del bibliófilo; ${ }^{24}$ o quizá perteneciera al entorno familiar o socioliterario del poeta sevillano -tal vez su hijo, Diego Guillén de Ávila, también poeta y célebre traductor-. Otra conjetura posible se basa en las cuatro últimas piezas que se inician con un poema de Bartolomé de Torres Naharro, y podrían apuntar a un entorno italiano (Rodado Ruiz en prensa). Según esto, quizá haya que relacionar a Torres Naharro con la selección y copia de esas piezas, bien durante su estancia en Italia, bien a su regreso; al menos uno de los poemas es suyo, y aparece acompañado de otras tres piezas muy próximas a sus gustos literarios en temas y formas.

Dutton fechó el cancionero a finales del siglo XV (c.I495) (I982: I34; I990-9I: 4, I97), y Faulhaber no se aleja de esa cronología (c.I49I-I5oo, BETA Manid ı220, CNUM 26I). El papel empleado y el análisis paleográfico no permiten acotar la fecha con la precisión deseable, pues es posible situar la copia del cancionero en un arco amplio, entre la última década del siglo XV y el primer tercio del XVI. En todo caso, los poemas de Hernando Colón y la pieza de Torres Naharro, juntamente con las otras tres obras finales, se copian con posterioridad al primer decenio del siglo, si atendemos a las fechas probables de composición; ${ }^{25}$ y no debe olvidarse que aunque cambian los copistas en esas secciones, las letras comparten tipología y tiempos (especialmente, la de la sección colombina) con las que se emplean en el resto del cancionero. ${ }^{26}$ Así pues, los resultados globales del estudio indican más bien la segunda década del siglo XVI.

$$
3 \cdot 2 S A ı b
$$

SAiob transmite I 47 obras, todas en castellano a excepción de un anónimo villancico bilingüe en castellano/latín (ı842 G 6957, SAıob-I8I). ${ }^{27}$ A diferencia de SAıoa, no recoge ninguna pieza en prosa. La columna de equivalencias entre la numeración nueva y la antigua permite observar con claridad dónde se producen las pérdidas de folios y las alteraciones de orden (Wittstein 19O7: 2993OO; Rodado Ruiz 2003: 482): ${ }^{28}$

24. SAioa no pudo pertenecer a don Hernando porque habría quedado registrado en sus repertorios.

25. Es factible pensar que las piezas de Hernando Colón (I488-I539) sean obras de juventud, es decir, compuestas, aproximadamente, a partir de I5o6; en cuanto al poema de Torres Naharro, el arco cronológico para su composición abarca desde I5O9 a I5I7, fecha de su publicación en el volumen Propalladia (Nápoles, I5I7). Véase Rodado Ruiz (en prensa).

26. Es sabido que existe un dilatado arco temporal, que arranca de fines del siglo XV y se adentra en las primeras décadas del XVI, en el que la tipología escritural oscila entre «dos polos que sirven de punto de partida: cortesana y humanística» (Marín Martínez - Ruiz Asencio r987: 2, 75).

27. Me atengo al cómputo de Dutton que contabiliza como una pieza más la canción que figura a continuación del decir de Santillana «Gentil dama tal pareçe» (IDi767, SAıob-85; «Coraçon a dios te do», ID430i C I767, SAıob-85-I).

28. Es Wittstein y no Kerkhoff (como afirma erróneamente Faulhaber, BETA CNUM 26I) quien estableció por primera vez las correspondencias entre la numeración antigua y la moderna. 


\begin{tabular}{|c|c|c|c|}
\hline \multicolumn{3}{|c|}{ Numeración nueva } & Numer: \\
\hline \multirow[t]{2}{*}{ Fols. } & $95^{-\mathrm{II} 2}$ & $=$ & I-I8 \\
\hline & I34 & $=$ & I9 \\
\hline & I32-I33 & $\begin{array}{c}= \\
\text { (faltan } 4 \text { folios) }\end{array}$ & $2 \mathrm{O}-2 \mathrm{I}$ \\
\hline & I35-г38 & $\begin{array}{c}= \\
\text { (faltan I9 folios) }\end{array}$ & $26-29$ \\
\hline & I39-I/4I & $\begin{array}{c}= \\
\text { (faltan I2 folios) }\end{array}$ & $49^{-5} 5^{\mathrm{I}}$ \\
\hline & $\mathrm{I} 42$ & $\begin{array}{c}= \\
\text { (faltan I2 folios) }\end{array}$ & 64 \\
\hline & I $43-\mathrm{I} 47$ & $\begin{array}{c}= \\
(\text { faltan } 3 \text { folios })\end{array}$ & $77^{-8 \mathrm{I}}$ \\
\hline & I $48-\mathrm{I} 63$ & $=$ & $85^{-\mathrm{IOO}}$ \\
\hline & ІІ8-І29 & $\begin{array}{c}= \\
\text { (falta I folio) }\end{array}$ & IOI-II2 \\
\hline & I3O-I3I & $\begin{array}{c}= \\
\text { (faltan I4 folios) }\end{array}$ & II4-II5 \\
\hline & ІІ3-ІІ7 & $=$ & I3O-I34 \\
\hline
\end{tabular}

Como se deduce del análisis paleográfico, la intervención de muchas manos y el descuido de la copia invitan a considerar varias fases en la confección y escritura de esta colectánea, pero en su estadio inicial, el eje rector es la disposición por autores. El compilador no se arriesga y abre el manuscrito con un grupo de obras del Marqués de Santillana, que forma la primera sección homogénea del conjunto. También se ha ocupado de insertar sendas preguntas y respuestas de don Íñigo y Juan de Mena, en una de las cuales participan también Antón de Montoro y Juan Agraz. Esta parte inicial se ve afectada por los errores de encuadernación del manuscrito en el f. II2 donde acaba el Doctrinal de privados, tras el cual es preciso insertar el f. I34 (I9 antiguo) en el que continúan las obras del Marqués, que se completan con las composiciones que figuran en los ff. I32I33 (2O-2I ant.). En la segunda mitad de la compilación, figura otra sección más breve con piezas de Santillana, tal vez no previstas en un principio, que un lector-corrector cotejó con otro manuscrito de sus obras, como ya se ha visto. Entre ambos grupos, SAiob transmite una completa muestra de la obra del Marqués con piezas destacadas. ${ }^{29}$

Tras el bloque de Santillana se suceden otros módulos reservados a un autor principal que, en ocasiones, dan entrada también a intercambios de preguntas y respuestas con otros poetas (en los de Montoro y Mena, por ejemplo). De este modo, se siguen secciones homogéneas dedicadas a Garci Sánchez de Badajoz, Gómez Manrique, Antón de Montoro, Juan de Mena y Cartagena. Solo algunas piezas sueltas ajenas a los mencionados se colocan entre dichos bloques, quizá para limitar y marcar cambio de sección: por ejemplo, la Regla a los galanes, de Diego de Valera, entre la sección de Santillana y la de Sánchez de Badajoz; una pieza de Gonzalo de Monzón entre las de Montoro

29. Se seleccionan la Comedieta de Ponza, el decir sobre la muerte de don Enrique de Villena, la Querella de amor, el decir a una doncella que partió de Toledo, (texto repetido en esta colección (IDi767), como ya se ha visto, e indicio que puede corroborar la génesis en varias fases), el Triunfete de amor, el Planto de la reina Margarida, el Doctrinal de privados, textos completos o casi completos del Infierno y el Sueño, algunos decires y otras piezas breves. 
y Mena; y una pregunta de Jorge Manrique con su respuesta, entre Mena y Cartagena. Pero el criterio dispositivo no parece que se rompa hasta que acaba la sección de Cartagena, a pesar de las numerosas pérdidas de folios (5off.).

Cabe deducir lo dicho porque las pérdidas no se deben solo al descuido, al paso por muchas manos o a los efectos del tiempo, sino más bien al celo riguroso de algún lector. Sufren mutilaciones textos problemáticos desde el punto de vista religioso o político: por ejemplo, las Leçiones de Job en caso de amor, de Garci Sánchez, fueron censuradas porque en algún momento pasaron a ser consideradas blasfemas. Faltan los folios 22-25 (ant.) que muy probablemente contenían obras de este autor, dado que el folio I35 (26 ant.) recoge el Infierno, al que le faltan los primeros versos. Tras el Claroscuro y el Sueño de Badajoz figura la Querella de la gobernación de Gómez Manrique, texto que se ve afectado por una importante pérdida de folios (I9). También es muy probable que allí se recogieran obras de Gómez Manrique, ya que no hay ninguna otra en el resto del cancionero y resulta extraña su ausencia en tan amplia e ilustre selección de autores. A continuación, nuevas censuras afectan a las obras de Montoro y dejan incompletos o acéfalos varios poemas, algunos en versión única. ${ }^{\circ}$ La siguiente falta se produce tras el f. 147 y afecta a unas coplas de Juan de Mena en las que celebra la batalla de Olmedo de I 445 .

Nuevas pérdidas se detectan en la parte final del cancionero. Así, en el f. I29 figura la Misa de amor de Juan de Dueñas a la que afecta la pérdida de una hoja, que fue arrancada del cuaderno, ya que las estrofas conservadas están tachadas; y la última mutilación interrumpe una obra política de Baena (IDo285), el decir que enbio [...] al señor rey sobre las discorcordias (sic) por que manera podran ser remediadas.

En todo caso, en esta segunda parte -menos extensa que la primera- se rompe el criterio dispositivo por autores prácticamente hasta los folios finales del cancionero, en donde encontramos un intercambio burlesco de piezas entre Juan Agraz y Juan Marmolejo, que queda también interrumpido. A partir del f. I54 en el que van finalizando las obras de Cartagena, se suceden piezas de varios poetas en caprichosa mezcla: entre otros, Astorga, Diego de Burgos, Soria, Pero Álvarez, Íñigo Velasco, Estúñiga, Caltraviesa, Baena, Rodríguez del Padrón, Diego de San Pedro o Móxica, además de la segunda sección de Santillana y algunas obras más de Mena. Bien es verdad que de algunos autores se copian dos o tres obras seguidas, pero ello no indica más que la intención de mantener cierto orden en la copia. Esta segunda parte parece responder a un criterio organizativo diferente: el compilador no quiso renunciar a aprovechar los materiales que había logrado reunir, probablemente en una fase posterior de búsqueda y recolección, y decide incorporar al cancionero su particular repertorio de autores varios; por eso añade obras de Santillana y Mena cuyas secciones ya figuran en los cuadernos iniciales, de lo que se deduce que no las tenía cuando se copiaron dichos cuadernos..$^{3^{\mathrm{r}}}$

Así pues, parece probable la compilación del cancionero en fases -y también la copia-, así como el empleo de materiales procedentes de varias tradiciones, algunas perdidas como las que conforman el abultado grupo de unica (69). Se advierte cuidado y coherencia en la selección y en la disposición de las piezas, también en la parte final, como se ha visto. Así se explica la inclusión de sendas respuestas de Montoro y Juan Agraz a una pregunta de Mena dirigida a Santillana (IDi765, I766), inmediatamente después de la respuesta del marqués, que transmite en versión única SAıob;

30. Tal vez recogieran esos folios las coplas tachadas blasfemas que dirigió a la reina Isabel y que tantas respuestas suscitaron. Entre ellas, la de Francisco Vaca en el Cancionero General (ID6ro4, iICG-I27), y la de Álvaro de Brito en el Cancioneiro de García de Resende (ID52IO, I6RE-II9), quien compuso además una glosa sobre las mismas coplas (ID 5334, I6RE-I2O).

3. Tampoco se puede descartar que interviniera más de un compilador o artífice. 
también explica la inclusión de otros tres textos (otros unica) para cerrar las obras de Mena en la primera sección, las Coplas que fizo Juan de Mena al conde de Niebla quando tomaron Córdova, y sendas respuestas nuevamente de Juan Agraz y Antón de Montoro (IDı805, I806, I807). Es decir, es indiscutible que hay acopio de materiales heterogéneos, de obras poco difundidas, y que existe un claro interés por agrupar poemas relacionados. Este interés explica el espacio en blanco que se deja tras una pregunta de Santillana (IDo3O2, SAiob-92) esperando encontrar una respuesta -o más de una, que es lo habitual- para insertarla después, puesto que deja un espacio medido (no una plana completa, por ejemplo).

SAıob contiene I 47 composiciones de las cuales 69 son versiones únicas; un primer grupo de composiciones son datables entre I430 -fecha en la que Santillana escribe el Planto de la reina Margarida - y I 453 -fecha de composición del Doctrinal de Privados-; por ejemplo, las coplas de Juan de Mena al conde de Niebla (IDi805) datan de I444, y el tratado de Juan Agraz sobre la muerte del conde de Mayorga (IDo380), de I437. Quiere esto decir que existe un núcleo de composiciones que remiten a una cronología temprana (poetas nacidos entre I37 y I 430), y un segundo grupo, en el que figuran Cartagena, Diego de San Pedro o Garci Sánchez, que nos sitúan en el último cuarto del siglo XV y en las primeras décadas del XVI (poetas nacidos entre I43I y I475). Obviamente, la fecha de composición de las obras no es determinante para establecer la cronología en la confección del manuscrito, ya que la copia puede ser muy posterior, como de hecho lo es; además, el compilador puede haber usado modelos recientes, o bien copias antiguas pertenecientes a ramas altas de la tradición. Esto último es lo que parece haber ocurrido con las piezas seleccionadas de Santillana, Cartagena o Sánchez de Badajoz (Rodado Ruiz 2003, 20I9).

Si atendemos a los materiales antologados, resulta evidente que el factor cronológico no fue determinante -ni en la primera ni en la segunda parte- ya que recoge autores de distintas generaciones en todo el repertorio. SAıob parece ser una antología para uso personal: el compilador pretende reunir obras ya añosas en ese momento, pero consideradas imprescindibles -selecciona grandes maestros (Santillana, Mena, Gómez Manrique) e ingeniosos vates (Montoro, Estúñiga) - con otras de su tiempo que firman poetas más recientes, aunque ya suficientemente conocidos y también avalados por la fama (Cartagena, Garci Sánchez). Es probable que su intención fuera también salvaguardar junto a obras consagradas, antiguas o modernas, otras escasamente difundidas y que no llegaron a la imprenta, tradiciones que se extinguen con este cancionero, a juzgar por el abultado número de unica..$^{2}$

Respecto a la fecha probable de la compilación, Dutton (I982: I, I34; I99O-9I: 4, 232) la considera de principios del siglo XVI, mientras que Faulhaber (BETA Manid ı22O, CNUM $26 \mathrm{I}$ ) propone la misma datación que para SAтoa (ca.I49I-I5OO). Los indicios codicológicos y paleográficos reunidos hasta el momento apuntan a una cronología similar a la del primer cancionero, es decir, primeras décadas del siglo XVI.

\section{${ }_{4}$ Conclusiones}

El presente estudio demuestra que el análisis codicológico de manuscritos permite desentrañar incógnitas de apariencia irresoluble y despejar problemas de transmisión y recepción textual que superan en mucho el mero ejercicio descriptivo. Cada uno de los aspectos de estricta materialidad resulta mucho más fructífero de lo inicialmente esperado, cuando todos se ponen al servicio del

32. Vicenç Beltran comenta este tipo de antología a propósito del Cancionero de Herberay (I999: 25). 
estudio de un códice sobre el que se aplica el foco de atención. Se trata, entonces, de observar el códice como objeto físico, como recipiente de los textos poéticos que han dejado en él el rastro de su trayectoria, del entorno en el que nacieron, se copiaron o se difundieron, o de las circunstancias que los transformaron.

Como la mayoría de los códices facticios, SAıo es un volumen accidental que, sin embargo, ha servido para preservar dos cancioneros. Hago mías las palabras de Menéndez Pidal cuando dijo que «alguna hipótesis es siempre necesaria, pues sin ella no podríamos salir de un atontado agnosticismo» (1956: 64). A juzgar por la fecha probable del papel de las hojas de guarda, es posible que en el entorno salmantino del Colegio Mayor de Cuenca, en los primeros decenios del siglo XVII, un bibliotecario -seguramente más interesado por los libros de Derecho y Teología que por la lírica- encargara la encuadernación en un solo volumen de los dos cartapacios manuscritos de poesía medieval, aparentemente semejantes por contener poemas antiguos, que quizá se hallaban juntos en los anaqueles que él custodiaba, si es que el desinterés, la censura o la incuria de encargados y lectores no habían hecho ya de uno de ellos un montón de cuadernos descosidos e incompletos.

Así pues, fuera intencionada la decisión -reunir un único volumen de poesía medieval-o fruto del error de no revisar lo que se estaba encuadernando, aquel hecho sirvió como seguro de conservación para ambos manuscritos.

Contemporáneos en su confección, los dos cancioneros transmiten en conjunto una buena muestra de la poesía cancioneril castellana, desde las generaciones de mediados del siglo XV hasta los poetas más jóvenes que escriben a principios del XVI. Coinciden, entre otros pormenores, en su gestación en varias fases y en la participación de numerosos copistas, pero son divergentes en su génesis de partida: el primero se proyecta inicialmente sobre la copia de un modelo anterior y se vincula con los cancioneros que transmiten la obra de Pero Guillén de Segovia; SAıob se configura, en principio, sobre la tradición manuscrita del Marqués de Santillana, Mena, Montoro, Cartagena y Garci Sánchez. Como se ha podido ver, las directrices que cabe deducir del desarrollo de ambos repertorios modifican el planteamiento originario y acaban dando entrada a materiales heterogéneos.

SAıo agrupa dos colectáneas de cronología cercana, divergentes en concepción y factura, que testimonian el interés permanente de los nuevos lectores del siglo Xvi por la poesía de cancionero, por los temas y metros tradicionales castellanos, en plena eclosión del lirismo italianizante en la Península. 


\section{Obras citadas}

Aubrun, Charles. I953. 'Inventaire des sources pour l'étude de la poésie castillaine au XVe siècle', in Estudios dedicados a Menéndez Pidal (Madrid: CSIC), Iv: 297-330

Amador de los Ríos, José (ed.). I852. Obras de Don Ínigo López de Mendoza, Marqués de Santillana (Madrid: [s.n.]) <http://go.uv.es/Rau4ibW>

Beltran, Vicenç. 1999. 'Tipología y génesis de los cancioneros: la organización de los materiales', in Estudios sobre poesía de cancionero, ed by Vicenç Beltran, Begoña Campos, Luzdivina Cuesta and Cleofé Tato (A Coruña: Toxosoutos), pp. 9-54

Beltrán de Heredia, Vicente O.P. 197. 'Diego Ramírez de Villaescusa, fundador del Colegio Mayor de Cuenca en Salamanca', in Cartulario de la Universidad de Salamanca (1218-1600) (Salamanca: Ediciones Universidad de Salamanca), III: 405-442

BETA: Biblioteca Española de Textos Antiguos (versión electrónica del BOOST). 1984-. Charles B. Faulhaber, Ángel Gómez Moreno, David Mackenzie, John J. Nitti, and Brian Dutton Bibliography of Old Spanish Texts (Madison, WI: Hispanic Seminary of Medieval Studies) <http://sunsite. berkeley.edu/Philobiblon/Beta> [accessed IO-OI-2O2O]

Blecua, José Manuel. I970 [1952]. 'Corrientes poéticas en el siglo XVI’, in Sobre poesía de la Edad de Oro (Madrid: Gredos), pp. II-24

Briquet, C.M. I888. Papiers et filigranes des Archives de Gênes (1154 à 1700) (Genève: H. Georg Libraire-Éditeur) <http://go.uv.es/ $4 \mathrm{nbLlBg}>$

Briquet, C.M. 1984 [1907]. Les Filigranes, dictionnaire historique des marques de papier (Hildesheim-Zurich-Nueva York: Georg Olms Verlag) <http://go.uv.es/OnBCY $3 \mathrm{~b}>$

Carabias Torres, Ana María. I983. El Colegio Mayor de Cuenca en el siglo XVI: estudio institucional (Salamanca: Ediciones Universidad de Salamanca)

Dutton, Brian. 1982. Catálogo-índice de la poesía cancioneril del siglo XV (Madison: Hispanic Seminary of Medieval Studies)

Dutton, Brian; Krogstad, Jineen (ed.). I99O-9I. El cancionero del siglo XV, c. 1300-1520, Biblioteca Española del Siglo XV, Maior, I-7 (Salamanca: Universidad de Salamanca)

Entrambasaguas, Joaquín de. 1943. La biblioteca de Ramírez de Prado (Madrid: CSIC)

Fink-Errera, G. I959. 'À propos des Bibliothèques d'Espagne’, Scriptorium, I3: 89-II8 < http:// go.uv.es/iK 5 i $5 \mathrm{Vr}^{2}>$

González Cuenca, Joaquín. 1978. 'Cancioneros manuscritos del prerrenacimiento', Revista de Literatura, 40: I77-2I5

Lapesa, Rafael. 1982 [1962]. 'Poesía de cancionero y poesía italianizante', in De la Edad Media a nuestros días (Madrid: Gredos), pp. I45-I7 I

Lilao Franca, Óscar; Castrillo González, Carmen. 2002. Catálogo de manuscritos de la Biblioteca Universitaria de Salamanca (Salamanca: Ediciones de la Universidad de Salamanca), II: Manuscritos 1680-2777

Marín Martínez, Tomás; Ruiz Asencio, José Manuel (dir.). 1987. Paleografía y diplomática, 2 vols (Madrid: UNED) 
Martín Hernández, Francisco. 196r. La formación clerical en los colegios universitarios españoles (1371-1563) (Vitoria: Eset)

Menéndez Pidal, Ramón. I956. 'Cantos románicos andalusíes, continuadores de una lírica latina vulgar’, in España, eslabón entre la cristiandad y el Islam (Madrid: Espasa-Calpe)

Mestre Sanchis, Antonio; Catalá Sanz, Jorge A.; Pérez García, Pablo (ed). (2002). Francisco Pérez Bayer Diario histórico de la reforma de los seis colegios mayores de Salamanca, Valladolidy Alcalá (València: Generalitat Valenciana), pp. 69-75

Moreno, Manuel. 2OI2. 'Descripción codicológica MNi3 Mss. 3755-3765, Biblioteca Nacional, Madrid.', in CIM: Cancioneros impresos y manuscritos < www.cancioneros.org/descripciones/ index.aspx $>$

Moreno Hernández, Carlos (ed.). 1989. Pero Guillén de Segovia Obra poética (Madrid: Fundación Universitaria Española)

Mussafia, A. I9O2. 'Per la bibliografia dei Cancioneros Spagnuoli', Denkschriften der Kaiserlichen Akademie der Wissenschaften, Philosophisch-Historische Classe, 47 : $\mathrm{I}-24$ < http:/ /go.uv.es/ $\underline{\mathrm{x} 2 \mathrm{xj} \mathrm{XDt}}>$

Navarro, Andrés. I782. Índice de los manuscritos que se hallan en la Biblioteca del Colegio Mayor de Cuenca de la Universidad de Salamanca (Ms. 2952, Biblioteca Nacional de España) $<\underline{\text { http:// }}$ go.uv.es/eV 4 urz $\mathrm{Y}>$

Pérez Priego, Miguel Ángel (ed.). I983. Marqués de Santillana Poesías completas (Madrid: Alhambra)

Ramos Ruiz, Isabel. 2009. 'Celebración y significado del VII centenario de la fundación de la Universidad de Salamanca en el curso académico 1953-I954', Historia de la Educación, 28: 233$257<$ http://go.uv.es/KCaBDop $>$

Rodado Ruiz, Ana M. 200o. 'Notas para la edición de SAıo', in Actas del VIII Congreso Internacional de la Asociación Hispánica de Literatura Medieval, ed. by M. Freixas, S. Iriso and L. Fernández (Santander: Consejería de Cultura del Gobierno de Cantabria), II: I547-I557

Rodado Ruiz, Ana M. 2003. 'Nuevas notas para la edición de SAıo', in Cancioneros en Baena: Actas del II Congreso Internacional Cancionero de Baena, ed. by Jesús L. Serrano Reyes (Baena: Ayuntamiento de Baena). I: 48I-493

Rodado Ruiz, Ana M. 20i6. 'El Cancionero Antiguo de Salamanca (SAıoa): materiales de un códice de poesía medieval', eHumanista: Journal of Iberian Studies, 32: $36 \mathrm{I}-373<\underline{\text { http://go.uv.es/ }}$ $\mathrm{pD}_{5} \mathrm{~V}_{3} \mathrm{~F}_{3}>$

Rodado Ruiz, Ana M. 2orza. 'Poesía única y deturpación textual en SAıoa', in Variación y testimonio único: la reescritura de la poesía, ed. by Josep Lluís Martos (Alacant: Universitat d’Alacant), pp. $259^{-2} 7^{8}$

Rodado Ruiz, Ana M. 20I7b. 'Variantes, variaciones e imprenta: SAıoa y IICG', Revista de Literatura Medieval, 29: 197-223< $\underline{\text { http://go.uv.es/zKs4Rmd }>}$

Rodado Ruiz, Ana M. 20I9. 'La transmisión textual de la poesía de Garci Sánchez de Badajoz: LBI, MNi4 y SAıob’, in Pragmáticas y metodologías para el estudio de la poesía medieval, ed. by Josep Lluís Martos and Natalia A. Mangas (Alacant: Universitat d'Alacant), pp. I9-5I

Rodado Ruiz, Ana M. (2020). 'De bibliografía y poesía: Hernando Colón y su legado literario', Edad de Oro, 39: I7-40, DOI https://doi.org/IO.I5366/edador02O2O.39.0OI 
Rodado Ruiz, Ana M. (en prensa). 'Los poemas finales de SAioa: edición crítica y estudio literario', in Actas del XVIII Congreso Internacional de la Asociación Hispánica de Literatura Medieval

Rodríguez Díaz, Elena E. 2004. 'Indicios codicológicos para la datación de los manuscritos góticos castellanos', Historia. Instituciones. Documentos, 3I: 543-558 <http://dx.doi.org/IO.I2795/ $\underline{\mathrm{HID}}><$ http://go.uv.es/2pgMxO5$>$

Rohland de Langbehn, Regula (ed.). 1997. Marqués de Santillana Comedieta de Ponza, sonetos, serranillas y otras obras (Barcelona: Crítica)

Sánchez Mariana, Manuel. 1993. Bibliófilos españoles: desde sus orígenes hasta los albores del siglo $X X$ (Madrid: Biblioteca Nacional-Ministerio de Cultura-Ollero \& Ramos Editores)

Sánchez Prieto, Ana B.; Martínez Dávila, Roger L. 20I5. 'La copia del texto: categorías genéricas de la escritura manuscrita y su análisis', in Curso de Codicología <http:// codicologia.atspace.cc/ contenidos/o6Copia/o6-O3-AnalisisPaleogr.html $>$ [accessed 2O-OI-2O2O]

Simón Díaz, José. 1963. Bibliografía de la literatura hispánica (Madrid: CSIC), III

Tavira y Almazán, Antonio. Indice de los libros manuscritos de los colegios mayores de San Bartolomé, Cuenca, el Arçobispo y Oviedo de Salamanca (Ms. 44O4, Biblioteca Nacional de España) $\langle\underline{\text { http://go.uv.es/TWHqBT5 }>}$

Vàrvaro, Alberto. I964. Premesse ad un'edizione critica delle poesie minori di Juan de Mena (Napoli: Liguori)

Wittstein, Aaron. 1907. 'An Unedited Spanish Cancionero', Révue Hispanique, I6: 295-333 $\langle\underline{\text { http://go.uv.es/gt6FHoI }}>$ 


\section{Apéndice r: Índice deSAıoa}

$\left[f . r^{r}\right]$ «Tabla de las obras que siguen en este cancionero:

- Los salmos penitenciales, a i

- Quando Roma conquistava, a v

- Respuesta de Pero Guillén, a vi

- Respuesta de Pero Guillén a una carta en metros que Gómez Manrique envió a Diego Arias, contador mayor, a vii

- Unas de Gómez Manrique sobre la muerte del marqués de Santillana, a xii

- Tratado de Diego de Burgos sobre la muerte del marqués de Santillana, a xxiii

- Otros salmos penitenciales que ordenó Pero Guillén, a xliii

- La Salve Regina trovada, a li

- Dezir de Pero Guillén a la muerte del condestable de Castilla, don Álvaro de Luna, a liiii

- Dezir de Pero Guillén a un amigo lisonjero, a lvi

- Dezir de Pero Guillén quando se desposó, a lvii

- Dezir de Pero Guillén sobre amor, a lviii

- Dezir de Pero Guillén al día del Juizio, a lxiii

- Dezir de Pero Guillén contra Pobreza, a lxiiii

- Dezir de Pero Guillén al rey don Hernando luego que reinó, a lxv

- Canción de Juan de Viana

- Otra al viernes de la Cruz

- Otra canción suya

- Envinción del Juego de los naipes, a lxvi

- Otro dezir contra la muerte, a lxxi

- Canción de Alonso de Lira

- Otra del mesmo

- Otra suya

- Dezir de Juan Agraz quando se tornó paparresola, a lxxii

- Canción de Juan de Torres

- Pero Guillén a amor

- Dezir de Pero Guillén a una dama caritativa, a lxxiii

- Dezir de Pero Guillén difirido al arçobispo de Toledo, a lxxiiii

- Dezir de Pero Guillén a los milagros del calaboço, a lxxvi

- Dezir de Alfonso Álvarez de Illescas, a lxxviii

- Dezir de Pero Guillén dirigido al que sigue su voluntad, a lxxix» 


\section{Apéndice 2: Tablas secuenciales de obras y autores}

\section{SAioa}

\begin{tabular}{|c|c|c|c|}
\hline ID & Autor / Rúbrica & Incipit/explicit & Testimonios \\
\hline І697 & $\begin{array}{l}\text { Diego de Valera, Salmos } \\
\text { penitençiales }\end{array}$ & $\begin{array}{l}\text { No te rremienbres amor } \\
\text { goviernas por la tu mano }\end{array}$ & SAioa-I $\left(2^{r}\right)$ \\
\hline I698 S I697 & $\begin{array}{l}\text { Diego de Valera, Salmo } \\
\text { de veaticorum }\end{array}$ & $\begin{array}{l}\text { Vien aventurados son / } \\
\text { goviernas por la tu mano }\end{array}$ & SAioa-2 $\left(2^{v}\right)$ \\
\hline I699 S I697 & $\begin{array}{l}\text { Diego de Valera, Salmo } \\
\text { de domine ne yn furore }\end{array}$ & $\begin{array}{l}\text { no quieras rredarguyr / } \\
\text { gouiernas por la tu mano }\end{array}$ & SAioa-3 $\left(2^{\mathrm{v}}-3^{\mathrm{r}}\right)$ \\
\hline I700 S I697 & $\begin{array}{l}\text { Diego de Valera, Salmo } \\
\text { de miserere mey deus }\end{array}$ & $\begin{array}{l}\text { miserere mey cupido / } \\
\text { goviernas por la tu mano }\end{array}$ & SAioa-4 $\left(3^{\mathrm{r}-\mathrm{v}}\right)$ \\
\hline I7OI S I697 & $\begin{array}{l}\text { Diego de Valera, Salmo } \\
\text { de domine exaudi } \\
\text { oraçionem men }\end{array}$ & $\begin{array}{l}\text { oye señor mi oraçion / } \\
\text { goviernas por la tu mano }\end{array}$ & SAioa- $5\left(3^{v}-4^{r}\right)$ \\
\hline I7O2 S I697 & $\begin{array}{l}\text { Diego de Valera, de } \\
\text { profundis clamavi a te } \\
\text { domine }\end{array}$ & $\begin{array}{l}\text { de lo mas vaxo del suelo / } \\
\text { goviernas por la tu mano }\end{array}$ & SAioa-6 $\left(4^{r-v}\right)$ \\
\hline I703 S I697 & $\begin{array}{l}\text { Diego de Valera, } \\
\text { dominexaudi oraçionen } \\
\text { mean }\end{array}$ & $\begin{array}{l}\text { plega te señor oyr / } \\
\text { goviernas por la tu mano }\end{array}$ & SАгоа- $7\left(4^{\mathrm{v}}-5^{\mathrm{r}}\right)$ \\
\hline O535 & Diego de Valera, Ledania & $\begin{array}{l}\text { o soverana señora / que } \\
\text { non me puedo valer }\end{array}$ & SAтоа-8 $\left(5^{\mathrm{r}-\mathrm{v}}\right)$, MHI \\
\hline oog6 & $\begin{array}{l}\text { Gomez Manrique, Coplas } \\
\text { que fizo gomez manrrique }\end{array}$ & $\begin{array}{l}\text { quando rroma } \\
\text { conquystava / por falta } \\
\text { de governalles }\end{array}$ & 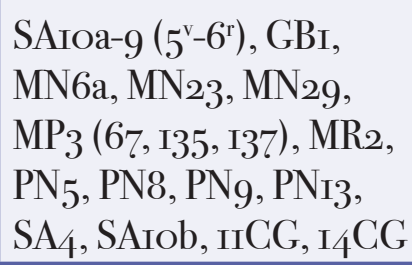 \\
\hline I7O5 R oog6 & $\begin{array}{l}\text { Pero Guillén, Coplas } \\
\text { de pero guyllen en } \\
\text { rrespuesta de quando } \\
\text { rroma conquystava }\end{array}$ & $\begin{array}{l}\text { es enuidia mucho braua / } \\
\text { de mostrar fingidos tales }\end{array}$ & SAioa-Io $\left(6^{\mathrm{v}}-8^{\mathrm{r}}\right)$ \\
\hline I706 P I707 & $\begin{array}{l}\text { Pero Guillén, Siquese } \\
\text { una Respuesta [...] a } \\
\text { vna carta en metros que } \\
\text { gomez manrrique enbio a } \\
\text { diego arias [...] }\end{array}$ & $\begin{array}{l}\text { si alguna venerable e } \\
\text { virtuoso cauallero / } \\
\text { persona virtuosa por } \\
\text { vereda de salvaçion }\end{array}$ & SAioa-II $\left(8^{r}-9^{r}\right)$ \\
\hline I7O7 R oo94 & $\begin{array}{l}\text { Pero Guillén, Siguense } \\
\text { los metros }\end{array}$ & $\begin{array}{l}\text { o Soberano yntelecto /y } \\
\text { con dinero }\end{array}$ & SAтоa-I2 $\left(9^{\mathrm{r}}-\mathrm{I} 3^{\mathrm{r}}\right)$ \\
\hline
\end{tabular}




\begin{tabular}{|c|c|c|c|}
\hline I708 & $\begin{array}{l}\text { Gómez Manrique, Gomez } \\
\text { manrrique sobre la } \\
\text { muerte del marques de } \\
\text { santillana [...] }\end{array}$ & $\begin{array}{l}\text { Mis sospiros despertad/ } \\
\text { mas que ante dolorido }\end{array}$ & 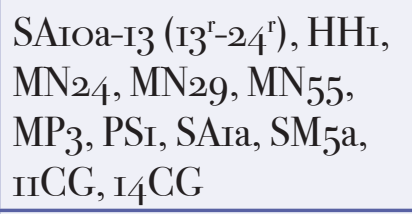 \\
\hline I7\%9 Р I7 IO & $\begin{array}{l}\text { Diego de Burgos, } \\
\text { Tratado que fizo diego de } \\
\text { Burgos [...] Prologo }\end{array}$ & $\begin{array}{l}\text { Muchas rrazones ay } \\
\text { ilustre / vuestra merced } \\
\text { como alla desea }\end{array}$ & SAioa-I $4\left(24^{\mathrm{r}}-28^{\mathrm{r}}\right)$ \\
\hline I ZIO & $\begin{array}{l}\text { Diego de Burgos, } \\
\text { Comiença el tratado } \\
\text { tryunfo del marques [...] }\end{array}$ & $\begin{array}{l}\text { tornado era febo a ver el } \\
\text { tesoro / amor y criança } \\
\text { tal yerro consiente }\end{array}$ & $\begin{array}{l}\text { SAIOa-I5 }\left(28^{\mathrm{r}}-44^{\mathrm{r}}\right), \mathrm{HH} \text {, } \\
\text { MN }_{55}, \text { IICG }\end{array}$ \\
\hline I7II P I7I2 & $\begin{array}{l}\text { Pero Guillén, Siguense los } \\
\text { salmos penitençiales que } \\
\text { ordeno pero guyllen [...] }\end{array}$ & $\begin{array}{l}\text { Muy caro e dilecto amigo } \\
\text { /voluntad mas por } \\
\text { ynorançia }\end{array}$ & SAıоa-I6 (44r-v), НН I \\
\hline I7I 2 & $\begin{array}{l}\text { Pero Guillén, syguese } \\
\text { otro prologo en metro }\end{array}$ & $\begin{array}{l}\text { Señor oye mis gemidos / } \\
\text { ofreçer }\end{array}$ & $\begin{array}{l}\text { SAIoa-I7 }\left(44^{\mathrm{v}}-45^{\mathrm{r}}\right), \text { НH, } \\
\text { IICG }\end{array}$ \\
\hline I7I3 $\mathrm{S}_{\text {I7I2 }}$ & $\begin{array}{l}\text { Pero Guillén, salmo } \\
\text { prymero }\end{array}$ & $\begin{array}{l}\text { Señor no me reprehendas } \\
\text { / a ty enclinados }\end{array}$ & $\begin{array}{l}\text { SAIOa-I8 }\left(44^{\mathrm{r}}-45^{\mathrm{r}}\right), \text { НH, } \\
\text { IICG }\end{array}$ \\
\hline I7I4 $\mathrm{S}_{\text {I7 }}$ I2 & $\begin{array}{l}\text { Pero Guillén, salmo } \\
\text { segundo }\end{array}$ & $\begin{array}{l}\text { muncho bien aventurados } \\
\text { / bravo leon }\end{array}$ & $\begin{array}{l}\text { SAioa-I9 }\left(45^{\mathrm{r}}-46^{\mathrm{r}}\right), \text { НН, } \\
\text { IICG }\end{array}$ \\
\hline${ }_{17}{ }_{5} \mathrm{~S}_{\text {I7 } 12}$ & $\begin{array}{l}\text { Pero Guillén, Salmo } \\
\text { terçero }\end{array}$ & $\begin{array}{l}\text { en tu saña no me aflijas / } \\
\text { syn temor }\end{array}$ & $\begin{array}{l}\text { SAioa-20 }\left(46^{\mathrm{r}}-47^{\mathrm{r}}\right) \text {, HН, } \\
\text { IICG }\end{array}$ \\
\hline I7I6 S I7I2 & $\begin{array}{l}\text { Pero Guillén, Salmo } \\
\text { quarto }\end{array}$ & $\begin{array}{l}\text { Señor ave piadad / ally } \\
\text { veras }\end{array}$ & $\begin{array}{l}\text { SAioa-2I (47r-48r), HНi, } \\
\text { IICG }\end{array}$ \\
\hline I7I7 $\mathrm{S}_{\text {I7I2 }}$ & $\begin{array}{l}\text { Pero Guillén, Salmo } \\
\text { quynto }\end{array}$ & $\begin{array}{l}\text { ynfinito rresplandor / Sus } \\
\text { symientes }\end{array}$ & $\begin{array}{l}\text { SAioa-22 }\left(48^{\mathrm{r}}-49^{v}\right), \text { HН, } \\
\text { IICG }\end{array}$ \\
\hline I7 $18 S_{\text {I } 712}$ & Pero Guillén, Salmo sesto & $\begin{array}{l}\text { de las baxuras que feziste } \\
\text { / carydades }\end{array}$ & $\begin{array}{l}\text { SAioa-23 }\left(49^{\mathrm{v}}-5 \mathrm{O}^{\mathrm{r}}\right) \text {, НН, } \\
\text { IICG }\end{array}$ \\
\hline I7I9 $S_{\text {I7I2 }}$ & $\begin{array}{l}\text { Pero Guillén, Salmo } \\
\text { setimo }\end{array}$ & $\begin{array}{l}\text { Señor oye mi oraçion / } \\
\text { feneçer }\end{array}$ & $\begin{array}{l}\text { SAioa-24 }\left(5 \mathrm{O}^{\mathrm{r}}-5^{\mathrm{I}}\right), \text { HНI, } \\
\text { IICG }\end{array}$ \\
\hline OO49 & $\begin{array}{l}\text { ¿Pero Guillén? Anónimo, } \\
\text { Siguese la salue rregina } \\
\text { [...] }\end{array}$ & $\begin{array}{l}\text { Pronto rrey en los } \\
\text { naçidos / al gran rrey } \\
\text { nuestro señor }\end{array}$ & $\begin{array}{l}\text { SAIoa-25 }\left(52^{\mathrm{r}-}-54^{\mathrm{v}}\right), \mathrm{GB} \text {, } \\
\text { PN } 4 \text {, PN8, PNi2, }\end{array}$ \\
\hline 1720 & $\begin{array}{l}\text { Pero Guillén, Siguese otro } \\
\text { dezir que fizo pero guilen } \\
\text { (sic) sobre la muerte de } \\
\text { don alvaro de luna [...] }\end{array}$ & $\begin{array}{l}\text { Como los tienpos } \\
\text { contraryos / secuçion } \\
\text { abra en la tierra }\end{array}$ & SAтоа- $26\left(55^{\mathrm{r}-5} 6^{\mathrm{v}}\right)$ \\
\hline $\mathrm{I} 72 \mathrm{I}$ & $\begin{array}{l}\text { Pero Guillén, Otro dezir } \\
\text { que fizo pero guillen a vn } \\
\text { amigo lisonjero [...] }\end{array}$ & $\begin{array}{l}\text { Señor mio quyen se ofreçe } \\
\text { / con animo carytativo }\end{array}$ & SAioa-27 $\left(56^{v}-57^{v}\right)$ \\
\hline
\end{tabular}




\begin{tabular}{|c|c|c|c|}
\hline 1722 & $\begin{array}{l}\text { Pero Guillén, Otro dezir } \\
\text { que fizo pero guyllen } \\
\text { quando se desposo [...] }\end{array}$ & $\begin{array}{l}\text { coraçon moryr moryr / te } \\
\text { arnesa }\end{array}$ & SAıоa-28 $\left(57^{\mathrm{v}-} 5^{8 v}\right)$ \\
\hline $\mathrm{I} 723$ & $\begin{array}{l}\text { Pero Guillén, Otro dezir } \\
\text { que fizo pero guyllen } \\
\text { sobre amor[...] }\end{array}$ & $\begin{array}{l}\text { a la ora que tarquyno / } \\
\text { deseo que me apasyona }\end{array}$ & SAıoa-29 $\left(59^{\mathrm{r}}-63^{\mathrm{v}}\right)$ \\
\hline I 724 & $\begin{array}{l}\text { Pero Guillén, Otro dezir } \\
\text { que fizo pero guyllen al } \\
\text { dia del juyzio }\end{array}$ & $\begin{array}{l}\text { temed pecadores el dia } \\
\text { aplazado / no gastes tu } \\
\text { vida asy por demas }\end{array}$ & SAioa-3o $\left(63^{\mathrm{v}}-64^{\mathrm{v}}\right)$ \\
\hline $\mathrm{I} 725$ & $\begin{array}{l}\text { Pero Guillén, Otro dezir } \\
\text { que fizo pero guyllen } \\
\text { contra pobreza [...] }\end{array}$ & $\begin{array}{l}\text { Maguer que saturno my } \\
\text { suerte guerrea / y con } \\
\text { diligençia procura tu vida }\end{array}$ & SAıоа- 3 I $\left(64^{\mathrm{v}}-65^{\mathrm{v}}\right)$ \\
\hline I 726 & $\begin{array}{l}\text { Pero Guillén, Otro dezir } \\
\text { que fizo pero guyllen al } \\
\text { rrey nuestro señor [...] }\end{array}$ & $\begin{array}{l}\text { ya que se amansa la } \\
\text { furya de mares / y fasta } \\
\text { en turquy a le ayan rreçelo }\end{array}$ & SAioa-32 $\left(65^{v}\right)$ \\
\hline 0020 & $\begin{array}{l}\text { Lope de Estúñiga, Lope } \\
\text { de çuñiga sobre amor }\end{array}$ & $\begin{array}{l}\text { Sy mis tristes } \\
\text { pensamyentos / tu } \\
\text { servidor }\end{array}$ & 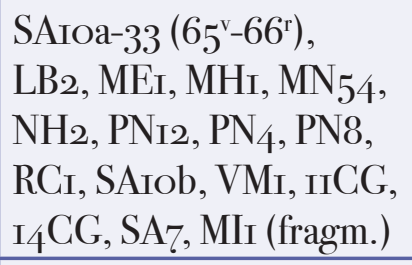 \\
\hline I727 R oO2O & $\begin{array}{l}\text { Pero Guillén, rrespuesta } \\
\text { de pero guyllen porque se } \\
\text { loo de mucho amador }\end{array}$ & $\begin{array}{l}\text { Tu a quyen } \\
\text { comedimyentos / ser } \\
\text { señor }\end{array}$ & SAioa-34 $\left(66^{r-v}\right)$ \\
\hline $\mathrm{I} 728$ & $\begin{array}{l}\text { Juan de Viana, cançion de } \\
\text { juan de vyana }\end{array}$ & $\begin{array}{l}\text { en tanto grado donzella / } \\
\text { por ser vos la cavsa della }\end{array}$ & SAıоa-35 $\left(66^{v}\right)$ \\
\hline I729 & $\begin{array}{l}\text { Juan de Viana, otra suya } \\
\text { alviernes de la cruz }\end{array}$ & $\begin{array}{l}\text { Sy alguna fue en } \\
\text { matarme / que dios } \\
\text { quyera perdonarme }\end{array}$ & SАгоа-36 $\left.366^{v}\right)$ \\
\hline $\mathrm{I} 73 \mathrm{O}$ & $\begin{array}{l}\text { Juan de Viana, otra } \\
\text { cançion suya }\end{array}$ & $\begin{array}{l}\text { pues que por tema tenes / } \\
\text { enforcame como judas }\end{array}$ & SAıоa-37 $\left(66^{\vee}\right)$ \\
\hline I73I & $\begin{array}{l}\text { Pero Guillén, Otro dezir } \\
\text { sobre amor que fizo pero } \\
\text { guillen }\end{array}$ & $\begin{array}{l}\text { Venyd amadores vereys } \\
\text { maravilla / que nunca } \\
\text { me pyenso ya ver byen } \\
\text { querido }\end{array}$ & $\begin{array}{l}\text { SAıоа- } 38\left(66^{\mathrm{v}}-67^{\mathrm{r}}\right), \mathrm{NH}_{2} \text {, } \\
\text { IICG, I4CG }\end{array}$ \\
\hline O593 Р 0594 & $\begin{array}{l}\text { Fernando de la Torre, } \\
\text { envinçion tomada sobre } \\
\text { el juego de los naypes [...] } \\
\text { Syguese vn prologo en } \\
\text { prosa. }\end{array}$ & $\begin{array}{l}\text { no creo nuevo seria } \\
\text { vuestra señora averme } \\
\text { mando / letras de oro en } \\
\text { la manera syguyente }\end{array}$ & $\begin{array}{l}\text { SAioa- } 39 \mathrm{P}\left(67^{\mathrm{r}-\mathrm{v}}\right), \mathrm{MN}_{54} \text {, } \\
\text { RCi }\end{array}$ \\
\hline O594 & $\begin{array}{l}\text { Fernando de la Torre, el } \\
\text { enperador }\end{array}$ & $\begin{array}{l}\text { Manyfiçençia e virtud/ } \\
\text { Ser(...) a vos e Reynar } \\
\text { (Texto final en prosa) }\end{array}$ & $\begin{array}{l}\text { SAioa-39 }\left(68^{\mathrm{r}}-7 \mathrm{I}^{\mathrm{v}}\right) \text {, } \\
\mathrm{MN}_{44}, \mathrm{MN}_{54}, \mathrm{RC}_{\mathrm{I}}\end{array}$ \\
\hline
\end{tabular}




\begin{tabular}{|c|c|c|c|}
\hline $\mathrm{O} 5 \mathrm{IO}$ & $\begin{array}{l}\text { Anónimo, Otro dezir } \\
\text { contra la muerte }\end{array}$ & $\begin{array}{l}\text { muerte que a todos } \\
\text { convidas / a ninguno mal } \\
\text { olvida }\end{array}$ & 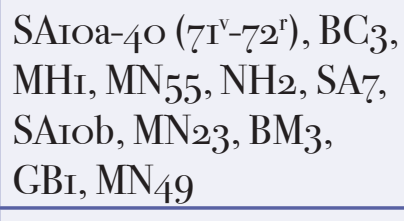 \\
\hline $\mathrm{I} 73^{2}$ & $\begin{array}{l}\text { Alonso de Lira, Cançion } \\
\text { alonso de lira }\end{array}$ & $\begin{array}{l}\text { por muy gran escuridad/ } \\
\text { del sol me quita deseo }\end{array}$ & SAioa-4I $\left(72^{r-v}\right)$ \\
\hline I733 & $\begin{array}{l}\text { Alonso de Lira, otra } \\
\text { cançion suya del dicho } \\
\text { alonso de lira }\end{array}$ & $\begin{array}{l}\text { o quien vos pudiese ver/ } \\
\text { pudiese quien lo desea }\end{array}$ & SAioa-42 $\left(72^{v}\right)$ \\
\hline $\mathrm{I} 734$ & Alonso de Lira, otra suya & $\begin{array}{l}\text { De las buenas e mas } \\
\text { vellas / valen mas que } \\
\text { todas ellas }\end{array}$ & SAioa- $43\left(72^{v}\right)$ \\
\hline $\mathrm{I} 735$ & $\begin{array}{l}\text { Juan Agraz, dezir que fizo } \\
\text { juan agras quando se fizo } \\
\text { paparresola }\end{array}$ & $\begin{array}{l}\text { catad que vos comere / } \\
\text { non me dan vna rraçion }\end{array}$ & SAioa-44 $\left(72^{\mathrm{v}}-73^{\mathrm{r}}\right)$ \\
\hline I 736 & $\begin{array}{l}\text { Juan de Torres, cançion } \\
\text { que ordeno juan de torres }\end{array}$ & $\begin{array}{l}\text { o maldida (sic) fermosura } \\
\text { / do non mora piedad }\end{array}$ & SAioa- $45\left(73^{\mathrm{r}}\right)$ \\
\hline I 737 & $\begin{array}{l}\text { Pero Guillén, a amor } \\
\text { pero guyllen }\end{array}$ & $\begin{array}{l}\text { doledvos de mys dolores / } \\
\text { que muero como maçias }\end{array}$ & SAioa- $46\left(73^{\mathrm{r}-\mathrm{v}}\right)$ \\
\hline I $73^{8}$ & $\begin{array}{l}\text { Pero Guillén, otro dezir } \\
\text { que fizo pero guyllen a } \\
\text { vna dama carytativa [...] }\end{array}$ & $\begin{array}{l}\text { Pues perdida la } \\
\text { verguença / sera vuestro } \\
\text { salvamyento }\end{array}$ & SAiоa-47 $\left(73^{\mathrm{v}}-74^{\mathrm{v}}\right)$ \\
\hline I739 Р I740 & $\begin{array}{l}\text { Pero Guillén, Siguese } \\
\text { otro dezir que fizo } \\
\text { pero guyllen dyrygido } \\
\text { o difirydo al señor } \\
\text { arçobispo de toledo [...] } \\
\text { prologo }\end{array}$ & $\begin{array}{l}\text { escrive seneca muy } \\
\text { manyfico Señor / otorgue } \\
\text { la eterna glorya poseer }\end{array}$ & $\begin{array}{l}\text { SAioa- } 48\left(74^{\mathrm{v}}-75^{\mathrm{v}}\right) \text {, } \\
\text { MNI2, MNI9, }\end{array}$ \\
\hline $\mathrm{I} 74 \mathrm{O}$ & $\begin{array}{l}\text { Pero Guillén, siguense los } \\
\text { metros }\end{array}$ & $\begin{array}{l}\text { Al tiempo que apolo } \\
\text { en fuerça creçia / color } \\
\text { en my rrostro pusyese } \\
\text { bermejo }\end{array}$ & $\begin{array}{l}\text { SAIoa- } 49\left(75^{\mathrm{V}}-77^{\mathrm{r}}\right) \text {, } \\
\text { MNI2, MNI9 }\end{array}$ \\
\hline $\mathrm{I} 74 \mathrm{I}$ & $\begin{array}{l}\text { Pero Guillén, Syguese } \\
\text { vn dezir [...] sobre los } \\
\text { mylagros del calaboço }\end{array}$ & $\begin{array}{l}\text { porque de nuestra } \\
\text { memorya / en tan triste } \\
\text { oratoryo }\end{array}$ & SAioa-5o $\left(77^{\mathrm{r}}-7^{\mathrm{v}}\right)$ \\
\hline $\mathrm{II} 5^{2}$ & $\begin{array}{l}\text { Alfonso Álvarez de } \\
\text { Villassandino, Alonso } \\
\text { alvarez de yllescas }\end{array}$ & $\begin{array}{l}\text { amygos tal cuyta mortal/ } \\
\text { no byve vyda segura }\end{array}$ & SAioa- $5 \mathrm{I}\left(7^{8 v}\right), \mathrm{PN}_{\mathrm{I}}$ \\
\hline $\mathrm{I} 742$ & Anónimo, cançion & $\begin{array}{l}\text { Sy porfuerça te partieres } \\
\text { / quando mas triste te } \\
\text { vieres }\end{array}$ & SAтоа- $5^{2}\left(78^{v}\right)$ \\
\hline
\end{tabular}




\begin{tabular}{|c|c|c|c|}
\hline $\mathrm{I} 743$ & $\begin{array}{l}\text { Pero Guillén, Este dezir } \\
\text { que se sygue [...] se diryge } \\
\text { al que sygue su voluntad } \\
\text { dexando el serviçio de } \\
\text { dios }\end{array}$ & $\begin{array}{l}\text { a ty que prrosygues por tu } \\
\text { voluntad / ten sobre todo } \\
\text { en dios esperança }\end{array}$ & $\begin{array}{l}\text { SAioa-53 }\left(79^{\left.\mathrm{r}-88^{\mathrm{r}}\right)} \text {, }\right. \\
\text { MNi2, MN55, MNi9 }\end{array}$ \\
\hline 0035 & $\begin{array}{l}\text { Lope de Estúñiga, } \\
\text { Comyença vn dezir de } \\
\text { lope de çuñiga }\end{array}$ & $\begin{array}{l}\text { o cabo de mys dolores / } \\
\text { de castidad }\end{array}$ & 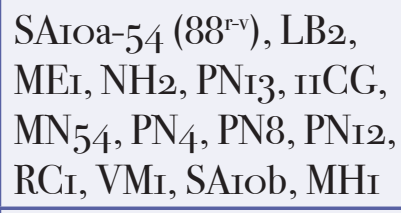 \\
\hline I744 & $\begin{array}{l}\text { Hernando Colón, } \\
\text { Cançion con su maldiçion } \\
\text { fecha por don hernando } \\
\text { colon }\end{array}$ & $\begin{array}{l}\text { o triste y o desdichado / y } \\
\text { esa me haz padeçer }\end{array}$ & SAтоа- $55\left(88^{v}-9 \mathrm{O}^{\mathrm{r}}\right)$ \\
\hline $\mathrm{I} 745$ & $\begin{array}{l}\text { Hernando Colón, } \\
\text { cançion del mesmo }\end{array}$ & $\begin{array}{l}\text { en peligro esta la vida / } \\
\text { do juez fue crueldad }\end{array}$ & SAioa- $56\left(9 \mathrm{O}^{\mathrm{r}}\right)$ \\
\hline 1746 & $\begin{array}{l}\text { Hernando Colón, } \\
\text { cançion del mesmo }\end{array}$ & $\begin{array}{l}\text { sy tu gesto gloryfica / con } \\
\text { el ver por desear }\end{array}$ & SAıoa-57 $\left(9 \mathrm{O}^{\mathrm{r}}\right)$ \\
\hline $\mathrm{I} 747$ & $\begin{array}{l}\text { Hernando Colón, otra } \\
\text { cançion del mesmo }\end{array}$ & $\begin{array}{l}\text { sy syntiese que no peno } \\
\text { / algud (sic) consuelo } \\
\text { tomar }\end{array}$ & SAioa-58 $\left(9 \mathrm{O}^{\mathrm{r}}\right)$ \\
\hline $\mathrm{I} 748$ & $\begin{array}{l}\text { Hernando Colón, otra } \\
\text { cançion del mesmo }\end{array}$ & $\begin{array}{l}\text { avnque ya syn esperança } \\
\text { / moryr siempre con la } \\
\text { vida }\end{array}$ & SAıоа-59 $\left(9 \mathrm{O}^{\mathrm{r}-\mathrm{v}}\right)$ \\
\hline I749 & $\begin{array}{l}\text { Hernando Colón, otra } \\
\text { cançion del mesmo }\end{array}$ & $\begin{array}{l}\text { no dudo que sy pudiese / } \\
\text { en la glorya que merezco }\end{array}$ & SАтоа-6о $\left(90^{v}\right)$ \\
\hline $\mathrm{I} 75^{\mathrm{O}}$ & $\begin{array}{l}\text { Hernando Colón, otra } \\
\text { cançion del mesmo }\end{array}$ & $\begin{array}{l}\text { vn penado pensamiento } \\
\text { / puso en vos my fe mas } \\
\text { firme }\end{array}$ & SAıоa-6I $\left(9 \mathrm{O}^{v}\right)$ \\
\hline $\mathrm{I} 75^{\mathrm{I}}$ & $\begin{array}{l}\text { Hernando Colón, otra } \\
\text { cançion del mesmo }\end{array}$ & $\begin{array}{l}\text { o desdichado amador / } \\
\text { syn esperança nynguna }\end{array}$ & SAıоa-62 $\left(90^{v}\right)$ \\
\hline $\mathrm{I} 75^{2}$ & $\begin{array}{l}\text { Hernando Colón, otra } \\
\text { cançion del mesmo }\end{array}$ & $\begin{array}{l}\text { pues syn cavsa so } \\
\text { culpado / que no me } \\
\text { quyeres valer }\end{array}$ & SAıоa-63 $\left(9 \mathrm{O}^{\mathrm{v}}-9 \mathrm{I}^{\mathrm{r}}\right)$ \\
\hline I753 & $\begin{array}{l}\text { Hernando Colón, otra } \\
\text { cançion del mesmo }\end{array}$ & $\begin{array}{l}\text { qual dolor puede sufryr } \\
\text { / porque del no me } \\
\text { consuele }\end{array}$ & SAıоa-64 $\left(9\right.$ I $\left.^{\mathrm{r}}\right)$ \\
\hline I 754 & $\begin{array}{l}\text { Hernando Colón, otra } \\
\text { cançion del mesmo }\end{array}$ & $\begin{array}{l}\text { amor yngrato rravioso / } \\
\text { por tenerte por señor }\end{array}$ & SAıоa-65 $\left(9 I^{\mathrm{r}}\right)$ \\
\hline $\mathrm{I} 755$ & $\begin{array}{l}\text { Hernando Colón, otra } \\
\text { cançion del mesmo }\end{array}$ & $\begin{array}{l}\text { el pago que amor ordena } \\
\text { / nunca jamas lo solto }\end{array}$ & SAıоa-66 $\left(9 \mathrm{I}^{\mathrm{r}-\mathrm{v}}\right)$ \\
\hline I $75^{6}$ & $\begin{array}{l}\text { Hernando Colón, } \\
\text { villançico del mesmo }\end{array}$ & $\begin{array}{l}\text { llora triste coraçon / que } \\
\text { rrazon as de llorar }\end{array}$ & SAıоа-67 $\left(9 \mathbf{I}^{v}\right)$ \\
\hline
\end{tabular}




\begin{tabular}{|c|c|c|c|}
\hline $\mathrm{I} 757$ & $\begin{array}{l}\text { Hernando Colón, } \\
\text { cançion del mesmo }\end{array}$ & $\begin{array}{l}\text { ay que soy lastimado / } \\
\text { que sufra pena rraviosa }\end{array}$ & SAıоa-68 $\left(9 \mathbf{I}^{v}\right)$ \\
\hline $\mathrm{I} 75^{8}$ & $\begin{array}{l}\text { Hernando Colón, otra } \\
\text { del mesmo }\end{array}$ & $\begin{array}{l}\text { o dicha çiega malvada / } \\
\text { pasando porty gran pena }\end{array}$ & SAтоа-69 $\left(9 \mathrm{I}^{\mathrm{v}}\right)$ \\
\hline I759 & $\begin{array}{l}\text { Hernando Colón, otra } \\
\text { cançion del mesmo }\end{array}$ & $\begin{array}{l}\text { amor me manda sofryr / } \\
\text { syn saber a qual seguyr }\end{array}$ & SAıоa-7o $\left(92^{r}\right)$ \\
\hline I760 & $\begin{array}{l}\text { Hernando Colón, otra } \\
\text { cançion del mesmo }\end{array}$ & $\begin{array}{l}\text { myll vezes desesperançal } \\
\text { feneçiendo con la vyda }\end{array}$ & SAioa-7I $\left(92^{\mathrm{r}}\right)$ \\
\hline I76I & $\begin{array}{l}\text { Anónimo, sin título ni } \\
\text { rúbrica }\end{array}$ & $\begin{array}{l}\text { Segund me aueys } \\
\text { demandado /contento } \\
\text { por ser tan bella }\end{array}$ & $\begin{array}{l}\text { SAıоo-72 }\left(92^{\mathrm{r}}-93^{\mathrm{r}}\right) \text {, } \\
\text { Propalladia }\left(5^{\mathrm{I}} 7\right)\end{array}$ \\
\hline I762 & Anónimo, Otra obra & $\begin{array}{l}\text { señor de vos he sabido / } \\
\text { harralla }\end{array}$ & SАıоа-73 $\left(93^{r-v}\right)$ \\
\hline I 763 & $\begin{array}{l}\text { Anónimo, Otra obra } \\
\text { (franco-italiano) }\end{array}$ & $\begin{array}{l}\text { Mon ami guarde la teta/ } \\
\text { a guardad la sua barreta }\end{array}$ & SAioa-74 $\left(93^{\mathrm{v}}-94^{\mathrm{r}}\right)$ \\
\hline I764 & Anónimo, Otra obra & $\begin{array}{l}\text { perdida de juventud / con } \\
\text { palabras de amistad }\end{array}$ & SAioa- $75\left(94^{r-v}\right)$ \\
\hline
\end{tabular}

\section{SAiob}

\begin{tabular}{|c|c|c|c|}
\hline ID & Autor / Rúbrica & Incipit & Testimonios \\
\hline OO53 & $\begin{array}{l}\text { Marqués de Santillana, } \\
\text { Dezir que fizo [...] } \\
\text { llamado comedieta de } \\
\text { ponça }\end{array}$ & $\begin{array}{l}\text { Ovos dubidantes creed } \\
\text { las estorias / despues } \\
\text { convertido en tanta } \\
\text { alegria }\end{array}$ & 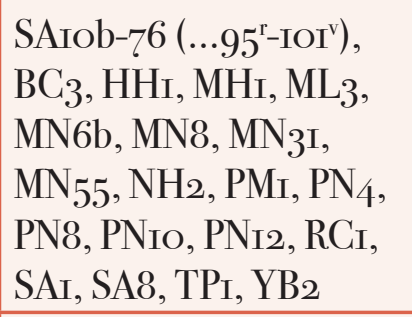 \\
\hline O3O5 & $\begin{array}{l}\text { Marqués de Santillana, } \\
\text { Elmarques [...] sobre la } \\
\text { muerte de don enrrique de } \\
\text { villena }\end{array}$ & $\begin{array}{l}\text { rrobadas abia el austro } \\
\text { e borea / como al pie del } \\
\text { monte por mi rrecontado }\end{array}$ & 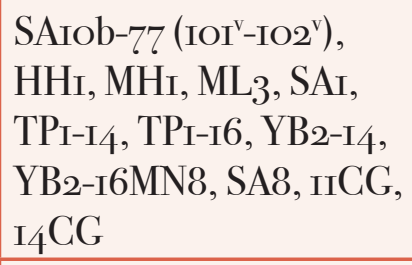 \\
\hline OI59 & $\begin{array}{l}\text { Marqués de Santillana, } \\
\text { Pregunta del marques } \\
\text { de santillana a juan de } \\
\text { mena }\end{array}$ & $\begin{array}{l}\text { Dezid juan de mena e } \\
\text { mostradme qual / mas } \\
\text { siempre guerrea al geno } \\
\text { vmanal }\end{array}$ & 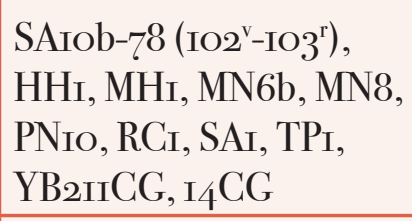 \\
\hline oI6o R oI59 & $\begin{array}{l}\text { Juan de Mena, Respuesta } \\
\text { de juan de mena }\end{array}$ & $\begin{array}{l}\text { en corte gran febo en } \\
\text { canpo anibal / codicia } \\
\text { llama por seso moral }\end{array}$ & $\begin{array}{l}\text { SAıob-79 (Iо3 }{ }^{\text {r) }} \text {, HН, } \\
\text { MHI, MN6b, MN8, } \\
\text { PNIo, RCi, SAISA3, TPI, } \\
\text { YB2, IICG, I4CG }\end{array}$ \\
\hline
\end{tabular}




\begin{tabular}{|c|c|c|c|}
\hline o329 & $\begin{array}{l}\text { Juan de Mena, pregunta } \\
\text { de juan de mena al } \\
\text { marques de santillana }\end{array}$ & $\begin{array}{l}\text { si gran fortaleza } \\
\text { tenplança y saber /y } \\
\text { nunca rreposan ni son } \\
\text { mas quietos }\end{array}$ & $\begin{array}{l}\text { SAIob-8o }\left(\mathrm{IO}^{\mathrm{r}}\right), \mathrm{LB} 2, \\
\text { MEIMHı, MN8SAI, TPi, } \\
\text { YB2IICG, I4CG }\end{array}$ \\
\hline o33o R o329 & $\begin{array}{l}\text { Marqués de Santillana, } \\
\text { rrespuesta del marques }\end{array}$ & $\begin{array}{l}\text { sy algo yo siento o se } \\
\text { conoçer / por medio } \\
\text { noturnos escuros y netos }\end{array}$ & $\begin{array}{l}\text { SAiob-8I }\left(\text { Iо }^{\text {r-v }}\right), \mathrm{LB}_{2}, \\
\text { MEI, MHг, MN8, SAI, } \\
\text { TPI, YB2, IICG, I4CG }\end{array}$ \\
\hline I765 R o329 & $\begin{array}{l}\text { Antón de Montoro, } \\
\text { rrespuesta [...] a esta } \\
\text { pregunta que hizo juan } \\
\text { de mena al marques de } \\
\text { santyllana }\end{array}$ & $\begin{array}{l}\text { a bos a quien sobra } \\
\text { poder y querer / el non } \\
\text { se esconde en logares } \\
\text { secretos }\end{array}$ & SAiob-82 (IO3 $\left.{ }^{v}\right)$ \\
\hline I766 R o329 & $\begin{array}{l}\text { Juan Agraz, Respuesta } \\
\text { [... I a juan de mena desta } \\
\text { pregunta que hizo al } \\
\text { marques de santillana }\end{array}$ & $\begin{array}{l}\text { yo huelgo poeta de } \\
\text { Regradeçer / en vna } \\
\text { pregunta do fallan } \\
\text { defectos }\end{array}$ & 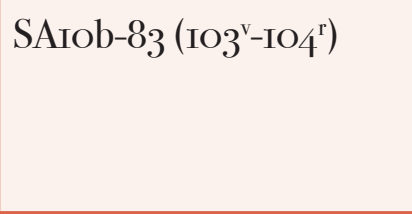 \\
\hline OI27 & $\begin{array}{l}\text { Marqués de Santillana, } \\
\text { el marques [...] estando } \\
\text { en la cama oyo a vn } \\
\text { camarero suyo [...] }\end{array}$ & $\begin{array}{l}\text { ya la gran noche pasava } \\
\text { / perder mi bien cuytado }\end{array}$ & $\begin{array}{l}\left.\text { SAIob-84 (IO4 } 4^{\mathrm{r}-\mathrm{v}}\right), \mathrm{LB}_{2}, \\
\text { MEI, MHI, ML3, MN8, } \\
\text { MN54, PNI3, PN8, RCI, } \\
\text { TPI, VMI, YB2, PNI2, } \\
\text { SA7, SA8, IICG }\end{array}$ \\
\hline I 767 & $\begin{array}{l}\text { Marqués de Santillana, } \\
\text { el marques [...] a vna } \\
\text { donzella que partio de } \\
\text { toledo }\end{array}$ & $\begin{array}{l}\text { gentil dama tal pareçe } \\
\text { /ya (\#:de) my se a } \\
\text { despedido }\end{array}$ & 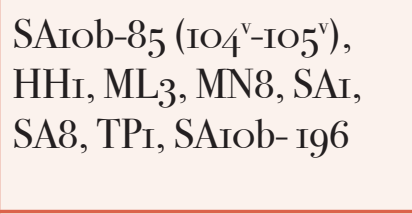 \\
\hline 43 ог C I7 67 & [Marqués de Santillana] & $\begin{array}{l}\text { coraçon a dios te do / } \\
\text { pues que su cativo so\#\#) }\end{array}$ & 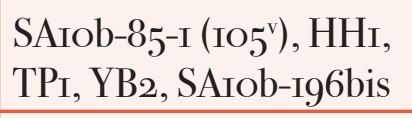 \\
\hline O29I & $\begin{array}{l}\text { Marqués de Santillana, el } \\
\text { marques [...] don yñigo } \\
\text { lopez }\end{array}$ & $\begin{array}{l}\text { sygiendo el plaçiente } \\
\text { estilo / contra mi } \\
\text { desmesurada }\end{array}$ & 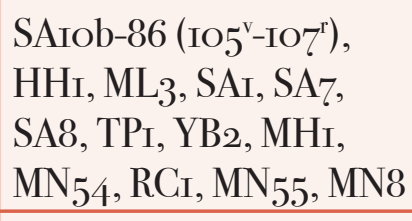 \\
\hline O289 & $\begin{array}{l}\text { Marqués de Santillana, el } \\
\text { marques [...] don yñigo } \\
\text { lopez }\end{array}$ & $\begin{array}{l}\text { al tiempo que va trando / } \\
\text { sy ge la rrecomendaron }\end{array}$ & 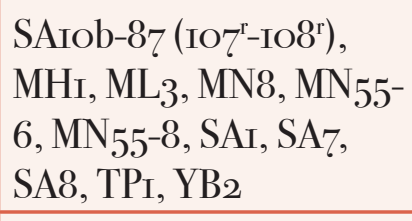 \\
\hline O3OI & $\begin{array}{l}\text { Marqués de Santillana, } \\
\text { el marques don ýnygo } \\
\text { López de Santillana }\end{array}$ & $\begin{array}{l}\text { a la ora que medea / } \\
\text { aquellas insines gentes }\end{array}$ & $\begin{array}{l}\text { SAIob-88 (Iо8- } \text { Io9 }^{\mathrm{r}} \text {, } \\
\text { MHı, ML3, MN8, MN55, } \\
\text { SAI, SA8, TPI, YB2, } \\
\text { IICG }\end{array}$ \\
\hline
\end{tabular}




\begin{tabular}{|c|c|c|c|}
\hline оіо6 & $\begin{array}{l}\text { Marqués de Santillana, } \\
\text { Dotrinal de pribados [...] } \\
\text { maestre de santiago }\end{array}$ & $\begin{array}{l}\text { vi tesoros ayuvntados / } \\
\text { gentes de todos estados }\end{array}$ & 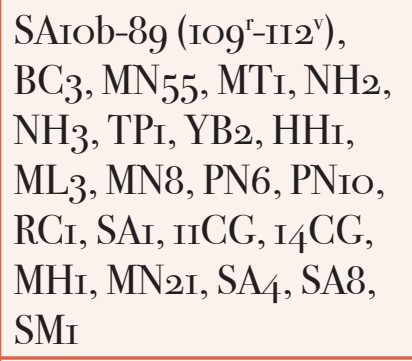 \\
\hline о3⿻ 6 & $\begin{array}{l}\text { Marqués de Santillana, el } \\
\text { marques de santillana a } \\
\text { la señora rreyna }\end{array}$ & $\begin{array}{l}\text { dios vos faga virtusa (sic) } \\
\text { / ylustre rreyna famosa }\end{array}$ & $\begin{array}{l}\text { SAiob-90 (I34), MHI, } \\
\text { MN8, SA8 }\end{array}$ \\
\hline оI65 & $\begin{array}{l}\text { Marqués de Santillana, el } \\
\text { marques Ýnygo López de } \\
\text { Mendoza haziendo vnas } \\
\text { preguntas sobre las cosas } \\
\text { deste mundo }\end{array}$ & $\begin{array}{l}\text { pregunto que es de } \\
\text { aquellos que fueron / por } \\
\text { que de aquestos ninguno } \\
\text { non veo }\end{array}$ & $\begin{array}{l}\left.\text { SAıob-9I ( } 134^{\mathrm{r}-\mathrm{v}}\right), \mathrm{MH}_{\mathrm{I}}, \\
\mathrm{ML}_{3}, \mathrm{MN}_{23} \text {, PNIO, RCi, } \\
\text { SAI, SA7, SA8, MN8, }\end{array}$ \\
\hline $\mathrm{O} 3 \mathrm{O} 2$ & $\begin{array}{l}\text { Marqués de Santillana, } \\
\text { pregunta de yñygo lópez } \\
\text { marques de Santillana }\end{array}$ & $\begin{array}{l}\text { gran rretorico eloquente / } \\
\text { çiençia pura con alteza }\end{array}$ & $\begin{array}{l}\text { SAırob-92 }\left(\mathrm{I} 34^{\mathrm{v}}, \mathrm{I}^{2} 2^{\mathrm{r}}\right) \text {, } \\
\text { MHI }\end{array}$ \\
\hline OO48 & $\begin{array}{l}\text { Marqués de Santillana, } \\
\text { protestaçion del marqués } \\
\text { yñygo lopez a su amiga }\end{array}$ & $\begin{array}{l}\text { antes el rrodante çielo / y } \\
\text { te oluidase }\end{array}$ & 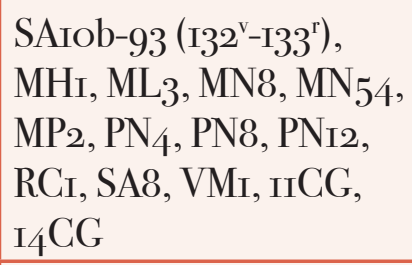 \\
\hline I768 & $\begin{array}{l}\text { Diego de Valençia } \\
\text { [Valera], rregla a los } \\
\text { galanes por diego de } \\
\text { valençia }\end{array}$ & $\begin{array}{l}\text { ardideza sin vfana / don } \\
\text { la fortuna otorgo }\end{array}$ & SAıob-94 (ז33v) \\
\hline I769 & $\begin{array}{l}\text { Garçi Sánchez de } \\
\text { Badajoz, las leçiones de } \\
\text { job en caso de amor [...] } \\
\text { badajoz }\end{array}$ & $\begin{array}{l}\text { pues amor quiere que } \\
\text { muera / en sus manos... }\end{array}$ & $\begin{array}{l}\left.\text { SAiob-95( }{ }^{\left(I 33^{v}\right.} \ldots\right), \mathrm{MN}_{\text {I4 }} \text {, } \\
\text { IICG, I4CG }\end{array}$ \\
\hline o662 & $\begin{array}{l}\text { [Garçi Sánchez de } \\
\text { Badajoz] }\end{array}$ & $\begin{array}{l}{[\ldots] \text { compasion[...]// }} \\
\text { ponerse an quando } \\
\text { mandaren }\end{array}$ & $\begin{array}{l}\text { SAıob-96 (...I355-I37r), } \\
\text { LBI, MNI4, IICG, I3 }{ }^{*} \text { BI, } \\
\text { I4CG }\end{array}$ \\
\hline O73I & $\begin{array}{l}\text { Garçi Sánchez de } \\
\text { Badajoz, esta es el } \\
\text { claroescuro de garçi } \\
\text { sanchez de badajoz }\end{array}$ & $\begin{array}{l}\text { el día infelix noturno / } \\
\text { que tenga la muerte çierta }\end{array}$ & $\begin{array}{l}\left.\text { SAIob-97 (I37 } 7^{\mathrm{r}-\mathrm{v}}\right), \mathrm{LBI} \text {, } \\
\mathrm{MNI} 4, \mathrm{I} 4 \mathrm{CG}, \mathrm{I}_{4}{ }^{*} \mathrm{BM}, \\
\mathrm{I}^{*}{ }^{*} \mathrm{BM}, \mathrm{IICG}\end{array}$ \\
\hline o697 & $\begin{array}{l}\text { Garçi Sánchez de } \\
\text { Badajoz, el sueño de [...] } \\
\text { badajoz }\end{array}$ & $\begin{array}{l}\text { la mucha tristeza mya } \\
\text { / de la qual pena soy } \\
\text { muerto }\end{array}$ & 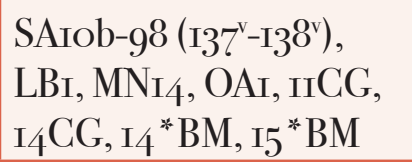 \\
\hline
\end{tabular}




\begin{tabular}{|c|c|c|c|}
\hline oog6 & $\begin{array}{l}\text { Gómez Manrique, obra } \\
\text { de gomez manrrique }\end{array}$ & $\begin{array}{l}\text { quando rroma } \\
\text { conquistava / por sendos } \\
\text { onbres pelean... }\end{array}$ & 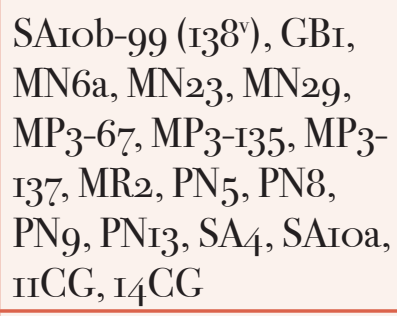 \\
\hline I 773 & -- & $\begin{array}{l}\text { [...]pues las fiestas } \\
\text { santas bellas / vaya a su } \\
\text { sepultura }\end{array}$ & SAiob-IOO $\left(\ldots \mathrm{I} 39^{\mathrm{r}-\mathrm{v}}\right)$ \\
\hline I774 & $\begin{array}{l}\text { Antón de Montoro, } \\
\text { montoro a quando rroma } \\
\text { conquistava rrespuesta }\end{array}$ & $\begin{array}{l}\text { en esos tienpos bogaua / } \\
\text { es dulçor con amargaura }\end{array}$ & SAiob-Iог (I39"), MP2 \\
\hline I 779 & $\begin{array}{l}\text { Gonçalo de Monçón, } \\
\text { pregunta [...] a anton de } \\
\text { montoro }\end{array}$ & $\begin{array}{l}\text { la gloria de vuestra fama } \\
\text { l o de mas mala memoria }\end{array}$ & SAıob-IO6 (I40²) \\
\hline I780 R I779 & $\begin{array}{l}\text { Antón de Montoro, } \\
\text { rrespuesta [...] a gonçalo } \\
\text { de monçon }\end{array}$ & $\begin{array}{l}\text { vos la çepa yo la rrama } \\
\text { de fama rresplanditoria }\end{array}$ & $\begin{array}{l}\text { SAIob-IO7 } \\
\left(\mathrm{I}_{4} \mathrm{O}^{\mathrm{r}-\mathrm{v}}\right)\end{array}$ \\
\hline I78I R I780 & $\begin{array}{l}\text { Gonçalo de Monçón, } \\
\text { Replicato de gonçalo de } \\
\text { monçon a esta pregunta }\end{array}$ & $\begin{array}{l}\text { Vos la miel y yo rretama / } \\
\text { rrespuesta satisfatoria }\end{array}$ & SAıob-IO8 (I40'-I4 $\left.\mathrm{I}^{\mathrm{r}}\right)$ \\
\hline I 782 & $\begin{array}{l}\text { Antón de Montoro, }[. . .] \\
\text { por la muerte de juan de } \\
\text { mena }\end{array}$ & $\begin{array}{l}\text { seneca holgaras ya / es } \\
\text { ganar con la del hïjo }\end{array}$ & $\begin{array}{l}\text { SAiob-IO9 }\left(\text { I }_{4} \mathrm{I}^{\mathrm{r}}\right), \mathrm{LB}_{3}, \\
\mathrm{SV}_{2}\end{array}$ \\
\hline I783 R огоо & $\begin{array}{l}\text { Antón [de Montoro], } \\
\text { otra de anton a canta tu } \\
\text { cristiana musa }\end{array}$ & $\begin{array}{l}\text { Vn tratado juan de mena } \\
\text { / y posistes rrima llena }\end{array}$ & SAIob-IIO (I4I') \\
\hline I 784 & $\begin{array}{l}\text { [Antón de Montoro], } \\
\text { Otra a vn cauallero que } \\
\text { su mujer desmando lo } \\
\text { quel mando }\end{array}$ & $\begin{array}{l}\text { Tras un virote perdido / y } \\
\text { en la casa del hodido }\end{array}$ & $\begin{array}{l}\text { SAIob-III }\left(\text { I }_{4} \mathrm{I}^{\mathrm{r-v}}\right), \mathrm{MN}_{\mathrm{I}} \text {, } \\
\text { IICG }\end{array}$ \\
\hline 1785 & $\begin{array}{l}\text { Antón de Montoro, } \\
\text { montoro çenando con } \\
\text { pero sanchez joiero }\end{array}$ & $\begin{array}{l}\text { Juro por dios yo venía / y } \\
\text { os hare dos mil plazeres }\end{array}$ & SAIob-II2 (I4I'v) \\
\hline I 786 & $\begin{array}{l}\text { Antón de Montoro, } \\
\text { montoro a vn scrivano } \\
\text { muy escaso que mercava } \\
\text { vn marauedi de pescado } \\
{[\ldots]}\end{array}$ & $\begin{array}{l}\text { çerca allá en la corredera } \\
\text { / que se mata sobre vn } \\
\text { sollo }\end{array}$ & SAıob-II3 (I4I \\
\hline I 787 & $\begin{array}{l}\text { Antón de Montoro, } \\
\text { montoro al mes de } \\
\text { hebrero porque llovio } \\
\text { mucho }\end{array}$ & $\begin{array}{l}\text { pesar al cuerpo de dios / } \\
\text { las rrodillas a la boca }\end{array}$ & $\begin{array}{l}\text { SAтоb-II4 (I4II }), \text { IICG, } \\
\text { I4CG, I9OB }\end{array}$ \\
\hline
\end{tabular}




\begin{tabular}{|c|c|c|c|}
\hline I788 & $\begin{array}{l}\text { Antón de Montoro, } \\
\text { cançion [...] a doña teresa } \\
\text { fija del duque }\end{array}$ & $\begin{array}{l}\text { estas muy bellas que son } / \\
\text { quando se miran los pies }\end{array}$ & SAIob-II5 (I4Iv), MNI9 \\
\hline I 789 & $\begin{array}{l}\text { Antón de Montoro, } \\
\text { montoro don pedro } \\
\text { porque lo amenazaron } \\
\text { (sic) }\end{array}$ & $\begin{array}{l}\text { como los canes con yra/ } \\
\text { y vos fazen canpo rraso }\end{array}$ & $\begin{array}{l}\left.\text { SAiob-II6 (I4I } \mathrm{I}^{\mathrm{v}}\right), \mathrm{LB}_{3} \text {, } \\
\mathrm{SV}_{2}\end{array}$ \\
\hline I 790 & 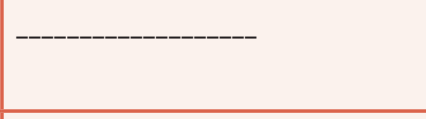 & $\begin{array}{l}\text { [... Jesta me pareçe el arca } \\
\text { / que su grandeza dexo }\end{array}$ & SAiob-II7 $\left(\ldots I 42^{r}\right)$ \\
\hline $\mathrm{O} 283$ & $\begin{array}{l}\text { Antón de Montoro, de } \\
\text { montoro a vn hïo de vn } \\
\text { pregonero de valladolid } \\
\text { [...] }\end{array}$ & $\begin{array}{l}\text { dezid amigo sois flor /o } \\
\text { tañedor de la flaute }\end{array}$ & $\begin{array}{l}\left.\text { SAIob-II8 ( } \text { I }_{4}{ }^{\mathrm{r}}\right), \mathrm{LB}_{3}, \\
\mathrm{MH}_{\mathrm{I}}, \mathrm{SV}_{2}, \mathrm{IICG}, \mathrm{I}_{4} \mathrm{CG}, \\
\mathrm{I}^{*} \mathrm{CO}, \mathrm{I}_{7}^{*} \mathrm{RM}, \mathrm{I} \mathrm{OB}\end{array}$ \\
\hline OI8I & $\begin{array}{l}\text { Antón de Montoro, } \\
\text { montoro a vn cavallero } \\
\text { borracho [...] }\end{array}$ & $\begin{array}{l}\text { no lo digo por blasfemia/ } \\
\text { y llevaros al infierno }\end{array}$ & $\begin{array}{l}\left.\text { SAiob-II9 (I42 }{ }^{\mathrm{r}}\right), \text { LBI, } \\
\text { MNI9, PNio, RCi, IICG, } \\
\text { I2 }{ }^{*} \mathrm{CP}\end{array}$ \\
\hline IIO9 & $\begin{array}{l}\text { Antón de Montoro, } \\
\text { montoro a vn cara de } \\
\text { borracho frances }\end{array}$ & $\begin{array}{l}\text { qual querrias mas } \\
\text { promete / se convirtiesen } \\
\text { en viñas }\end{array}$ & $\begin{array}{l}\text { SAIob-I2O }\left(\mathrm{I}_{4} 2^{\mathrm{r}}\right), \mathrm{LBI}, \\
\text { MNI9, }\end{array}$ \\
\hline оІ 76 & $\begin{array}{l}\text { Antón de Montoro, } \\
\text { montoro a vna beoda }\end{array}$ & $\begin{array}{l}\text { La viña muda su hoja / y } \\
\text { a la mañana tinaja }\end{array}$ & $\begin{array}{l}\left.\text { SAIob-I2I (I42 } 2^{\mathrm{r}}\right), \mathrm{LBI}, \\
\text { PNIO, RCI, }\end{array}$ \\
\hline I79I & $\begin{array}{l}\text { Antón de Montoro, } \\
\text { montoro porque le } \\
\text { dixeron que jugase cañas } \\
\text { gomes davila }\end{array}$ & $\begin{array}{l}\text { no jugais buen cavallero / } \\
\text { piernas coraçon y braço }\end{array}$ & $\begin{array}{l}\left.\text { SAIob-I22 (I42 }{ }^{\mathrm{r}}\right), \mathrm{LB}_{3}, \\
\text { MNI9-I38, MNI9-I26, } \\
\mathrm{MP}_{2}, \mathrm{SV}_{2},\end{array}$ \\
\hline $\mathrm{I} 79^{2}$ & $\begin{array}{l}\text { Antón de Montoro, } \\
\text { montoro vna cançion }\end{array}$ & $\begin{array}{l}\text { rraviosa hanbre de amor } \\
\text { /mas me dañas que me } \\
\text { dueles }\end{array}$ & $\begin{array}{l}\text { SAiob-I23 } \\
\left(\mathrm{I} 42^{\mathrm{r-v}}\right)\end{array}$ \\
\hline $\mathrm{I} 793$ & $\begin{array}{l}\text { Antón de Montoro, } \\
\text { montoro a vn cavallero } \\
\text { por dinero que le pedian } \\
\text { panaderas }\end{array}$ & $\begin{array}{l}\text { Señor non pecho nimedro } \\
\text { / diziendo paga traidor }\end{array}$ & $\begin{array}{l}\text { SAiob-I24 }\left(\mathrm{I}_{4} 2^{\mathrm{v}}\right), \mathrm{LB}_{3}, \\
\mathrm{SV}_{2}\end{array}$ \\
\hline $\mathrm{I} 794$ & $\begin{array}{l}\text { Antón de Montoro, } \\
\text { montoro cançion }\end{array}$ & $\begin{array}{l}\text { milveces duermo sin } \\
\text { (cama\#:gana) / en sueño } \\
\text { se me tornase }\end{array}$ & SAıob-I25 (I $\left.42^{\text {v }}\right)$ \\
\hline $\mathrm{I} 795$ & $\begin{array}{l}\text { Antón de Montoro, } \\
\text { montoro a alfonso de } \\
\text { jaen rrogandole enbiase } \\
\text { pescado a cordoua }\end{array}$ & $\begin{array}{l}\text { Virtuoso y no muy poco } \\
\text { /juro por dios que son } \\
\text { truchas }\end{array}$ & SAıob-I26 (I42 $\left.2^{\mathrm{v}}\right)$ \\
\hline I796 R I795 & $\begin{array}{l}\text { Alfonso de Jaen, } \\
\text { Respuesta de alfonso de } \\
\text { jaen }\end{array}$ & $\begin{array}{l}\text { a los nyños cata el choco } \\
\text { / por do muramos los dos }\end{array}$ & SAıob-I27 (I42v') \\
\hline
\end{tabular}




\begin{tabular}{|c|c|c|c|}
\hline I 797 & -ב---- & $\begin{array}{l}\text {...rresçiva vuestra } \\
\text { clemençia / de vos servir } \\
\text { por el suelo }\end{array}$ & SAıob-I28 (...I43') \\
\hline I $79^{8}$ & $\begin{array}{l}\text { [Antón de Montoro], } \\
\text { Otras que fizo a juan de } \\
\text { mena }\end{array}$ & $\begin{array}{l}\text { es coronista e mas } \\
\text { secretario / sobre los } \\
\text { cargos el de tanto jacario }\end{array}$ & SAıоb-І29 (I43ㄹ) \\
\hline I799 R I798 & $\begin{array}{l}\text { Juan de Mena, rrespuesta } \\
\text { dejuan de mena }\end{array}$ & $\begin{array}{l}\text { Sy no por cabsa de ser } \\
\text { neçesario / ante la cara } \\
\text { del viento contrario }\end{array}$ & SAıob-I3о (I $43^{\text {r) }}$ \\
\hline 1800 & $\begin{array}{l}\text { [Antón de Montoro], } \\
\text { otras que fizo al rrelator } \\
\text { despues que ovo salud }\end{array}$ & $\begin{array}{l}\text { Odeydad vera santa / de } \\
\text { los devinos decretos }\end{array}$ & $\begin{array}{l}\text { SAiob-I3I } \\
\left(\mathrm{I} 43^{\mathrm{r}-\mathrm{v}}\right)\end{array}$ \\
\hline I8OI & $\begin{array}{l}\text { Gonçalo de Monzón, } \\
\text { gonçalo de monton } \\
\text { fortuna (sic) }\end{array}$ & $\begin{array}{l}\text { yo so la alta fortuna / al } \\
\text { sabio tornarlo loco }\end{array}$ & SAıob-I32 (I $\left.43^{v}\right)$ \\
\hline оOIO & $\begin{array}{l}\text { Juan de Mena, otras } \\
\text { coplas de juan de mena }\end{array}$ & $\begin{array}{l}\text { ya no sufre mi cuydado } \\
\text { /guaresçer vn Juan de } \\
\text { mena }\end{array}$ & 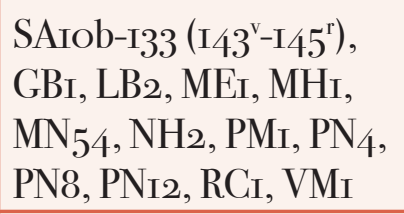 \\
\hline O337 & $\begin{array}{l}\text { Juan de Mena, Cançion } \\
\text { de juan de mena }\end{array}$ & $\begin{array}{l}\text { o quien visto nos vbiese } \\
\text { / que con muchos no } \\
\text { volviese }\end{array}$ & $\begin{array}{l}\text { SAıob-I34 } \\
\left(\mathrm{I} 45^{\mathrm{r}-\mathrm{v}}\right), \mathrm{MHI}, \mathrm{I} 2 \mathrm{MO}\end{array}$ \\
\hline 1802 & $\begin{array}{l}\text { [Juan II], Cançion que } \\
\text { fizo al señor rrey (sic) }\end{array}$ & $\begin{array}{l}\text { amor nunca pense / fasta } \\
\text { agora que lo se }\end{array}$ & $\begin{array}{l}\text { SAiob-I35 (I45), SA7, } \\
\text { I2MO }\end{array}$ \\
\hline OI63 & $\begin{array}{l}\text { Juan de Mena, Juan de } \\
\text { mena al rrey nuestro } \\
\text { señor quando salio de } \\
\text { madrigal [...] }\end{array}$ & $\begin{array}{l}\text { santa paz santo misterio / } \\
\text { nunca vos fuystes avaro }\end{array}$ & $\begin{array}{l}\left.\text { SAiob-I36 (I } 45^{\mathrm{v}}\right), \mathrm{MN} 64, \\
\text { I2MO, PNio, RCi }\end{array}$ \\
\hline I803 R ог63 & $\begin{array}{l}\text { [Juan II], rrespuesta que } \\
\text { fue fecha por el señor rrey } \\
\text { a juan de mena }\end{array}$ & $\begin{array}{l}\text { Juan de mena qual } \\
\text { ynperio / del culpante del } \\
\text { yñorado }\end{array}$ & $\begin{array}{l}\left.\text { SAIob-I37 (I } 45^{\mathrm{v}}-\mathrm{I} 46^{\mathrm{r}}\right) \\
\text { I2MO }\end{array}$ \\
\hline $105 \mathrm{I}$ & $\begin{array}{l}\text { Juan de Mena, Cançion } \\
\text { de juan de mena }\end{array}$ & $\begin{array}{l}\text { oya tu merçed y crea / } \\
\text { nunca puede ser perdido }\end{array}$ & 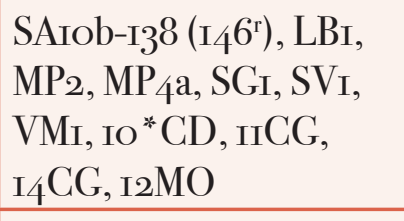 \\
\hline I8O4 & $\begin{array}{l}\text { Juan de Mena, Juan de } \\
\text { mena }\end{array}$ & $\begin{array}{l}\text { cuidar me faze cuidado / } \\
\text { menester }\end{array}$ & $\begin{array}{l}\left.\text { SAIob-I39 (I } 46^{\mathrm{r}}-\mathrm{I} 47^{\mathrm{r}}\right) \text {, } \\
\text { BMI, MEI, IICG, I4CG, } \\
\text { I2MO }\end{array}$ \\
\hline I805 & $\begin{array}{l}\text { Juan de Mena, Coplas } \\
\text { que fizo juan de mena al } \\
\text { conde de niebla [...] }\end{array}$ & $\begin{array}{l}\text { de vos se parte vençida / } \\
\text { para el cuerpo y para el } \\
\text { alma }\end{array}$ & SAıob-I4O (I47 \\
\hline
\end{tabular}




\begin{tabular}{|c|c|c|c|}
\hline I806 R I805 & $\begin{array}{l}\text { Juan Agraz, Respuesta } \\
\text { de juan agraz a juan de } \\
\text { mena }\end{array}$ & $\begin{array}{l}\text { esta tierra sostenida / es } \\
\text { mas llano que la palma }\end{array}$ & $\begin{array}{l}\text { SAiob-I4I } \\
\left(\mathrm{I} 47^{\mathrm{r}-\mathrm{V}}\right)\end{array}$ \\
\hline I807 R I805 & $\begin{array}{l}\text { Antón de Montoro, } \\
\text { Respuesta de anton de } \\
\text { montoro a juan de mena } \\
\text { y a juan de agraz }\end{array}$ & $\begin{array}{l}\text { Ogente tanto sentida / } \\
\text { pones brocado con xalma }\end{array}$ & SAıob-I42 (I $\left.47^{v}\right)$ \\
\hline I808 & $\begin{array}{l}\text { Juan de Mena, Coplas que } \\
\text { fizo juan de mena a los } \\
\text { cavalleros de castilla [...] }\end{array}$ & $\begin{array}{l}\text { La flaca varquilla de } \\
\text { mis pensamientos / dar } \\
\text { fin al libro callando al } \\
\text { presente... }\end{array}$ & $\begin{array}{l}\text { SAiob-I } 43\left({ }_{4} 47^{v} \ldots\right), \mathrm{SA}_{5} \text {, } \\
\mathrm{SM}_{\mathrm{I}}, 86^{*} \mathrm{RL}, \mathrm{BC}_{3}, \mathrm{CO} \text {, } \\
\mathrm{NH}_{5}, \mathrm{PN}_{7}\end{array}$ \\
\hline I809 & $\begin{array}{l}\text { Jorge [Manrique], } \\
\text { pregunta que fizo don } \\
\text { jorje sobre los hechos de } \\
\text { castilla }\end{array}$ & $\begin{array}{l}\text { entre bien y mal doblado } \\
\text { / la fuerça de la corriente }\end{array}$ & $\begin{array}{l}\left.\text { SAiob-I44 (...I48 }{ }^{r}\right) \text {, } \\
\text { MNig, IICG, I4CG }\end{array}$ \\
\hline I8IO R I809 & $\begin{array}{l}\text { Gonçalo de Córdova, } \\
\text { Respuesta de gonçalo de } \\
\text { cordova }\end{array}$ & $\begin{array}{l}\text { bien amar nunca mudado } \\
\text { / el siervo lealy sirviente }\end{array}$ & SAıob-I45 (I48), MNI9 \\
\hline I8II & Cartagena, De cartagena & $\begin{array}{l}\text { Pensamiento di a que } \\
\text { vienes / dare sin vos que } \\
\text { lo sea }\end{array}$ & $\begin{array}{l}\text { SAıob-I46 (I } 48 \text { r), IICG, } \\
\text { I4CG }\end{array}$ \\
\hline I812 & $\begin{array}{l}\text { Cartagena, cançion del } \\
\text { dicho cartagena }\end{array}$ & $\begin{array}{l}\text { Mi alma mala se para /y } \\
\text { el dolor del coraçon }\end{array}$ & $\begin{array}{l}\text { SAiob-I } 47, \text { IICG, I4CG } \\
\left(\mathrm{I} 4 \mathrm{~S}^{\mathrm{r}-\mathrm{v}}\right)\end{array}$ \\
\hline IO84 & $\begin{array}{l}\text { Marques de Astorga, } \\
\text { el marques [...] a vna } \\
\text { señora }\end{array}$ & $\begin{array}{l}\text { quiera dios que alguno } \\
\text { quieras / siendo yo } \\
\text { muerto primero }\end{array}$ & $\begin{array}{l}\text { SAiob-I48 (I48v), LBI, } \\
\text { MP } 4 \mathrm{a}\end{array}$ \\
\hline I8I3 & $\begin{array}{l}\text { Cartagena, Cartagena a } \\
\text { otro que esta enamodo de } \\
\text { su amiga (sic) }\end{array}$ & $\begin{array}{l}\text { Yo soy vos y vos sois yo } \\
\text { / que a mi el alma se me } \\
\text { sale }\end{array}$ & $\begin{array}{l}\text { SAтob-I } 49\left(\text { I }_{4} 8^{\mathrm{v}}-\mathrm{I} 49^{\mathrm{r}}\right) \text {, } \\
\text { IICG, I4CG }\end{array}$ \\
\hline I8I4 R I8I5 & $\begin{array}{l}\text { Cartagena, coplas que } \\
\text { hizo [...] al villançico de } \\
\text { ay santa maria [...] }\end{array}$ & $\begin{array}{l}\text { oidme señores / } \\
\text { esperança mia }\end{array}$ & SAıob-I5o (I49 $\left.{ }^{\mathrm{r}}\right)$ \\
\hline І8І 6 & $\begin{array}{l}\text { Cartagena, cartagena } \\
\text { villancico }\end{array}$ & $\begin{array}{l}\text { calledes fija / que no seria } \\
\text { verdad }\end{array}$ & $\begin{array}{l}\text { SAiob-I5I } \\
\left(\mathrm{I} 49^{\mathrm{r}-\mathrm{v}}\right)\end{array}$ \\
\hline O9I4 & $\begin{array}{l}\text { Cartagena, cartagena } \\
\text { sobre que le preguntavan } \\
\text { quien era su amiga [...] }\end{array}$ & $\begin{array}{l}\text { esta que queres saber / de } \\
\text { tanta perfeçion junta }\end{array}$ & 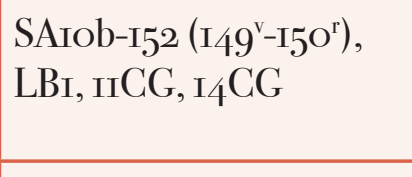 \\
\hline I8I7 & [Cartagena], cançion & $\begin{array}{l}\text { ved quan errado camino } \\
\text { / pagares yo lo adevino }\end{array}$ & SAıob-I53 (I50 $\left.{ }^{\mathrm{r}}\right)$ \\
\hline I8I8 & [Cartagena], cançion & $\begin{array}{l}\text { en my grave sentimiento / } \\
\text { es testigo de mi mal }\end{array}$ & $\begin{array}{l}\left.\text { SAIob-I54 ( } 5_{5} \mathrm{O}^{\mathrm{r}}\right), \mathrm{LN}_{\mathrm{I}}, \\
\mathrm{MN}_{\mathrm{I}}, \mathrm{MP}_{2}, \mathrm{IICG}_{\mathrm{I}} \mathrm{CG}\end{array}$ \\
\hline
\end{tabular}




\begin{tabular}{|c|c|c|c|}
\hline I8I9 & $\begin{array}{l}\text { Cartagena, de cartagena } \\
\text { a vna señora que le } \\
\text { pregunto como le yva con } \\
\text { su amiga [...] }\end{array}$ & $\begin{array}{l}\text { nora mala os conoçi/ } \\
\text { para vos y para my }\end{array}$ & SAIob-I55 (I50 \\
\hline 1820 & [Cartagena], cançion & $\begin{array}{l}\text { gran dolor tengo de mil } \\
\text { que asi fuese sea asy }\end{array}$ & SAıob-I56 (I50 \\
\hline I82I & [Cartagena] & $\begin{array}{l}\text { no sabes que e } \\
\text { contenplado / que no } \\
\text { torrelas dezia }\end{array}$ & $\begin{array}{l}\text { SAiob-I57 } \\
\left(\mathrm{I}_{5} \mathrm{O}^{\mathrm{r}-\mathrm{v}}\right)\end{array}$ \\
\hline I822 & $\begin{array}{l}\text { [Cartagena], } \\
\text { cançion }\end{array}$ & $\begin{array}{l}\text { pues en la vida ay fatiga / } \\
\text { y la vida la enemiga }\end{array}$ & SAıob-I58 (I50v) \\
\hline I823 & [Cartagena] & $\begin{array}{l}\text { pene el cuerpo goze el } \\
\text { alma / por que biva en } \\
\text { gozo el alma }\end{array}$ & SAıob-I59 (I50 \\
\hline I824 & [Cartagena], cançion & $\begin{array}{l}\text { mi vida tanto os desea/ } \\
\text { mas mal que no que no } \\
\text { sea }\end{array}$ & SAıоb-I6o (I50v) \\
\hline 7437 M 1825 & $\begin{array}{l}\text { [Cartagena], cançion } \\
\text { guardase para mas mal }\end{array}$ & $\begin{array}{l}\text { pues que mivida no } \\
\text { muere / guardase para } \\
\text { mas mal }\end{array}$ & SAıob-I6I (I50 \\
\hline I826 & [Cartagena], cançion & $\begin{array}{l}\text { la firmeza y esperanzal } \\
\text { he ya todo el mal sofrido }\end{array}$ & SAıob-I62 (I5I I $)$ \\
\hline I827 & [Cartagena], cançion & $\begin{array}{l}\text { pues murio mi corazon / } \\
\text { y lloren mi grand tristura }\end{array}$ & SAIob-I63 $\left(\right.$ I5I $\left.^{\mathrm{r}}\right)$ \\
\hline 1828 & [Cartagena], cançion & $\begin{array}{l}\text { muestrame vuestro valer } \\
\text { / o ganarme y no ser } \\
\text { vuestro }\end{array}$ & SAıob-I64 (I5Ir) \\
\hline I829 & [Cartagena], cançion & $\begin{array}{l}\text { tanto me a puesto en } \\
\text { cuydado / que no esperar } \\
\text { a pagarme }\end{array}$ & $\begin{array}{l}\text { SAiob-I65 } \\
\left(\mathrm{I}_{5} \mathrm{I}^{\mathrm{r}-\mathrm{v}}\right)\end{array}$ \\
\hline I830 & [Cartagena], cançion & $\begin{array}{l}\text { mis señores que an } \\
\text { perdido / y teneis se ... de } \\
\text { mano }\end{array}$ & SAıob-I66 (I5I $\left.{ }^{\mathrm{v}}\right)$ \\
\hline III2 & [Montoro], cançion & $\begin{array}{l}\text { no lo consyente firmeza / } \\
\text { andad amigos andad }\end{array}$ & $\begin{array}{l}\text { SAiob-I67 }\left(\text { I }_{5} \mathrm{I}^{v}\right), \text { LBI, } \\
\text { MNI9, MP2 }\end{array}$ \\
\hline I83I & [Cartagena], cançion & $\begin{array}{l}\text { Vluntad no trabajes } \\
\text { (sic) / congoxa es para } \\
\text { despues }\end{array}$ & $\begin{array}{l}\text { SAтob-I68 }\left(\mathrm{I}_{5} \mathrm{I}^{\mathrm{v}}\right), \text { IICG, } \\
\text { I4CG, I6RE }\end{array}$ \\
\hline I832 & [Cartagena], cançion & $\begin{array}{l}\text { Aunque mas querays } \\
\text { penarme / do no puedo } \\
\text { arrepentirme }\end{array}$ & 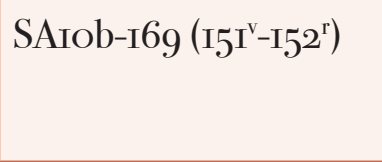 \\
\hline
\end{tabular}




\begin{tabular}{|c|c|c|c|}
\hline I833 & [Cartagena], cançion & $\begin{array}{l}\text { ves que mal tan peligroso } \\
\text { / i el rremedio este } \\
\text { dudoso }\end{array}$ & SAıob-I70 $\left(152^{\mathrm{r}}\right)$ \\
\hline I834 & [Cartagena] & $\begin{array}{l}\text { no me llameis enemigo / } \\
\text { que no el }\end{array}$ & SAIob-I7 I (I52 \\
\hline I835 & [Cartagena] & $\begin{array}{l}\text { tanta gloria tengo en } \\
\text { veros / pues que days la } \\
\text { vida en veros }\end{array}$ & SAIob-I72 $\left(152^{\mathrm{r}}\right)$ \\
\hline I836 & [Cartagena], cançion & $\begin{array}{l}\text { yo syn vos porque no } \\
\text { muero / o dolor de tal } \\
\text { catibo }\end{array}$ & SAIob-I73 $\left(152^{\mathrm{r}}\right)$ \\
\hline I837 & $\begin{array}{l}\text { Cartagena, Vna de } \\
\text { cartajena porque le pidio } \\
\text { por merced le hiziese vna } \\
\text { copla [...] }\end{array}$ & $\begin{array}{l}\text { Sy mill coplas por } \\
\text { correros / sobre qual mas } \\
\text { os mereçe }\end{array}$ & $\begin{array}{l}\text { SAiob-I74 } \\
\left(\mathrm{I} 5^{2^{r-v}}\right)\end{array}$ \\
\hline o89I & $\begin{array}{l}\text { Cartagena, coplas que } \\
\text { hizo cartajena a vna } \\
\text { señora por quien el } \\
\text { mucho penaba }\end{array}$ & $\begin{array}{l}\text { Ca fuerça del fuego } \\
\text { qalumbra que çiega (sic) } \\
\text { / mi flaco sentido segud } \\
\text { que debia (sic) }\end{array}$ & $\begin{array}{l}\text { SAIob-I } 75\left({ }^{1} 5^{2}{ }^{\mathrm{v}}-\mathrm{I} 54^{\mathrm{r}}\right) \\
\text { LBI, IICG, I4 }\end{array}$ \\
\hline I838 & [Cartagena], cançion & $\begin{array}{l}\text { es de tanta perfeçion / } \\
\text { menos themo la pasyon }\end{array}$ & SAıob-I76 (I54) \\
\hline I839 & $\begin{array}{l}\text { Cartagena, } \\
\text { De cartagena }\end{array}$ & $\begin{array}{l}\text { pues vos el bien que a } \\
\text { dios pido / y el mas a } \\
\text { vuestro mandado }\end{array}$ & SAıob-I77 (I54') \\
\hline піз8 & $\begin{array}{l}\text { Anónimo } \\
\text { [Juan del Encina] }\end{array}$ & $\begin{array}{l}\text { dos terribles } \\
\text { pensamientos / de los dos } \\
\text { qual tomare }\end{array}$ & $\begin{array}{l}\left.\text { SAiob-I78 ( } 54^{\mathrm{r}}\right), \mathrm{LB} \mathrm{I}^{-} \\
460, \mathrm{LBI}-462,96^{*} \mathrm{JE}, \\
\mathrm{I}^{*} \mathrm{RC}, 2 \mathrm{O}^{*} \mathrm{RC}, \mathrm{MP}_{4 \mathrm{a}}\end{array}$ \\
\hline 1840 & $\begin{array}{l}\text { Peña, } \\
\text { pregunta de peña a diego } \\
\text { de burgos [...] }\end{array}$ & $\begin{array}{l}\text { como natural deseo / y ba } \\
\text { cavallero en el }\end{array}$ & $\begin{array}{l}\text { SAiob-I79 } \\
\left(\mathrm{I} 54^{\mathrm{r}-\mathrm{v}}\right)\end{array}$ \\
\hline I84I R I840 & $\begin{array}{l}\text { [Diego de Burgos], } \\
\text { rrespuesta }\end{array}$ & $\begin{array}{l}\text { vos que las gracias de } \\
\text { orfeo / seres pena e pena } \\
\text { fiel }\end{array}$ & SAıоb-I80 (I54는 $\left.55^{\mathrm{r}}\right)$ \\
\hline I842 G 6957 & $\begin{array}{l}\text { Anónimo, villançico } \\
\text { parte en latin e parte en } \\
\text { rromanze }\end{array}$ & $\begin{array}{l}\text { heu mihi sine ventura / } \\
\text { tan malherido de ty }\end{array}$ & $\begin{array}{l}\left.\text { SAiob-I8I ( } 555^{\mathrm{r}}\right), \mathrm{MN}_{\mathrm{I}} \text {, } \\
\mathrm{MP}_{4} \mathrm{f}\end{array}$ \\
\hline I843 & Anónimo, cançion & $\begin{array}{l}\text { bien podeys darme } \\
\text { pasyon / nunca lo veran } \\
\text { losvibos }\end{array}$ & $\begin{array}{l}\text { SAiob-I82 } \\
\left(\mathrm{I} 55^{\mathrm{r}-\mathrm{V}}\right)\end{array}$ \\
\hline I844 & Anónimo, cançion & $\begin{array}{l}\text { o muerte quan mala eres / } \\
\text { nunca vienes }\end{array}$ & SAıоb-I83 (I55ำ) \\
\hline
\end{tabular}




\begin{tabular}{|c|c|c|c|}
\hline I845 & $\begin{array}{l}\text { Soria, } \\
\text { de soria }\end{array}$ & $\begin{array}{l}\text { veros y despues oyros / } \\
\text { porque no estan donde } \\
\text { estais }\end{array}$ & SAIob-I84 (I55') \\
\hline I846 & $\begin{array}{l}\text { Pero Álbarez, } \\
\text { de pero albarez }\end{array}$ & $\begin{array}{l}\text { do libertad es perdida / } \\
\text { tras la libertad la vida }\end{array}$ & SAıob-I85 (I55ㄴ) \\
\hline 1847 & Anónimo & $\begin{array}{l}\text { Ruego a dios que algund } \\
\text { traidor / sospires por el } \\
\text { traydor }\end{array}$ & SAıob-I86 (I55ํ) \\
\hline o68I & [Cartagena] & $\begin{array}{l}\text { o quan fuera de rrazon / } \\
\text { y que pene el corazon }\end{array}$ & SAıob-I87 (I55-I56 \\
\hline I849 & Anónimo, cançion & $\begin{array}{l}\text { amor de penada gloria / } \\
\text { corazon seso e memoria }\end{array}$ & SAıob-I88 (I5 $\left.6^{\mathrm{r}}\right), \mathrm{SV}$ I \\
\hline I850 & Anónimo & $\begin{array}{l}\text { Ase de entender asy / } \\
\text { todas quantas e mirado }\end{array}$ & SAıob-I89 ( $\left.156^{\text {r }}\right), \mathrm{MP}_{2}$ \\
\hline I85I & Anónimo & $\begin{array}{l}\text { dama por quien tengo } \\
\text { çertos / no se olbide mi } \\
\text { memoria }\end{array}$ & SAıob-I9o $\left(156^{6^{r}}\right)$ \\
\hline $185^{2}$ & $\begin{array}{l}\text { Íñigo Velasco, cançion de } \\
\text { yñigo velasco }\end{array}$ & $\begin{array}{l}\text { tan grandes males rreçibo } \\
\text { / porcos viy porque nos } \\
\text { veo }\end{array}$ & $\begin{array}{l}\left.\text { SAıob-I9I (I56 } 6^{\text {r }}\right), \text { IICG, } \\
\text { I4CG }\end{array}$ \\
\hline I853 & Anónimo, cançion & $\begin{array}{l}\text { despues de vuestra } \\
\text { partida / con mill temores } \\
\text { de olbido }\end{array}$ & SAıоb-I92 (I56 \\
\hline I854 & Anónimo, cançion & $\begin{array}{l}\text { o ventura que sostienes / } \\
\text { y rrecuerdas a mis males }\end{array}$ & $\begin{array}{l}\text { SAiob-I93 } \\
\left(\mathrm{I} 56^{r-v}\right)\end{array}$ \\
\hline 0028 & $\begin{array}{l}\text { Marqués de Santillana, } \\
\text { ynfierno de los } \\
\text { enamorados que fizo } \\
\text { Iñigo lopez marques }\end{array}$ & $\begin{array}{l}\text { la fortuna que non çesa / } \\
\text { si no es loco provado }\end{array}$ & 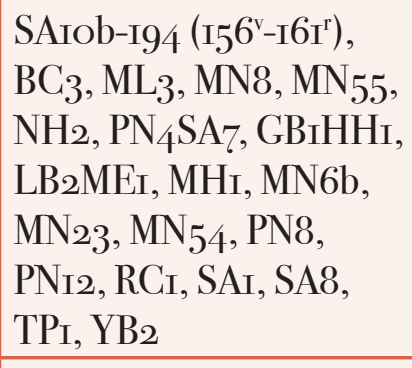 \\
\hline O290 & $\begin{array}{l}\text { Marqués de Santillana, } \\
\text { Otro dezir que fizo iñigo } \\
\text { lopez }\end{array}$ & $\begin{array}{l}\text { non es vmana la lunbre } \\
\text { dadme vida con rreposo }\end{array}$ & $\begin{array}{l}\left.\text { SAIob-I95 (I6I }{ }^{\mathrm{r}-v}\right), \text { MHI, } \\
\text { ML3, MN54, MN8, RCI, } \\
\text { SA8, TPI, YB2 }\end{array}$ \\
\hline $\begin{array}{l}\text { I } 767 \text { [repetido, } \\
\text { SAIob- } 85 \\
\left.\mathrm{IO}_{4}{ }^{\mathrm{v}}-\mathrm{IO}_{5}{ }^{\mathrm{v}}\right]\end{array}$ & $\begin{array}{l}\text { Marqués de Santillana, } \\
\text { Otro dezir que fizo el } \\
\text { dicho ynigo lopez }\end{array}$ & $\begin{array}{l}\text { gentil dueña tal pareçe / } \\
\text { pues que su contrarioso }\end{array}$ & 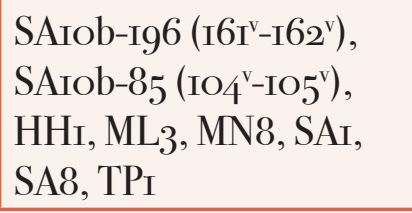 \\
\hline
\end{tabular}




\begin{tabular}{|c|c|c|c|}
\hline O299 & $\begin{array}{l}\text { Marqués de Santillana, } \\
\text { yñigo López de Mendoça }\end{array}$ & $\begin{array}{l}\text { oyan oyan los mortales } \\
\text { /so pensamyento } \\
\text { entregado }\end{array}$ & 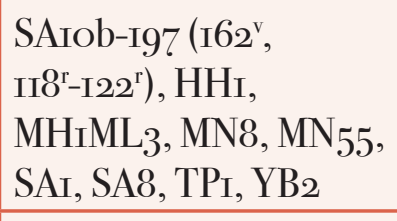 \\
\hline I855 & $\begin{array}{l}\text { Marqués de Santillana, } \\
\text { Serranylla de yñygo } \\
\text { López }\end{array}$ & $\begin{array}{l}\text { madrugando en } \\
\text { rrobedillo / loela su } \\
\text { enamorado }\end{array}$ & SAiob-I98 (I22 $\left.{ }^{\mathrm{r}}\right), \mathrm{SA}_{7}$ \\
\hline 0035 & $\begin{array}{l}\text { Lope de Estúñiga, } \\
\text { Coplas que fizo lope de } \\
\text { estunyga }\end{array}$ & $\begin{array}{l}\text { A cabo de mys dolores / } \\
\text { de castidad }\end{array}$ & 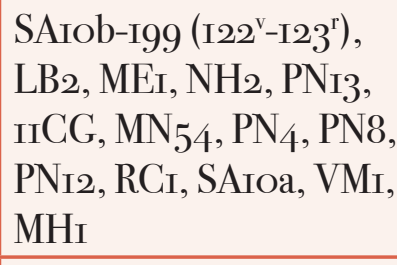 \\
\hline I856 & $\begin{array}{l}\text { Pedro de la Caltraviesa, } \\
\text { Dezir de pedro de la } \\
\text { caltrauiesa }\end{array}$ & $\begin{array}{l}\text { poderoso rrey despaña / } \\
\text { por la platica moral }\end{array}$ & SAIob-2OO (I2 $\left.3^{\mathrm{r}}-\mathrm{I} 24^{\mathrm{v}}\right)$ \\
\hline I857 & $\begin{array}{l}\text { Pedro de la Caltraviesa, } \\
\text { Coplas de pedro de la } \\
\text { caltrauiesa al señor Rey }\end{array}$ & $\begin{array}{l}\text { al Rey moro desues[tilde] } \\
\text { / con vn [punto] e con vn } \\
\text { [tilde] }\end{array}$ & 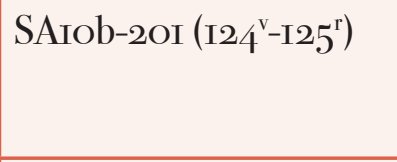 \\
\hline I858 & $\begin{array}{l}\text { Pedro de la Caltraviesa, } \\
\text { otra cançion de pedro de } \\
\text { la caltrauyesa }\end{array}$ & $\begin{array}{l}\text { mayor dolor a que siento } \\
\text { / mis penas e sentimyento }\end{array}$ & SAIob-2O2 (I25 ${ }^{\mathrm{r}}$ ) \\
\hline оот6 & $\begin{array}{l}\text { Lope de Estúñiga, } \\
\text { decir de lope de estunyga }\end{array}$ & $\begin{array}{l}\text { llorad mys llantos llorad } \\
\text { / quan desastrado naçi }\end{array}$ & 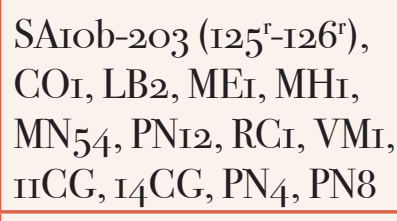 \\
\hline 0020 & $\begin{array}{l}\text { Lope de Estúñiga, decir } \\
\text { de lope de estunyga }\end{array}$ & $\begin{array}{l}\text { Simys tristes } \\
\text { pensamientos / tu } \\
\text { servidor }\end{array}$ & 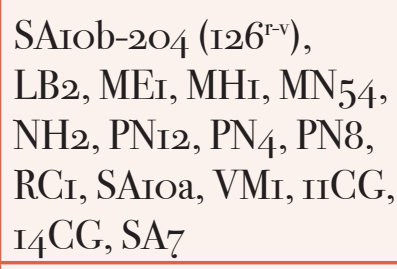 \\
\hline I859 & $\begin{array}{l}\text { [Múgica] } \\
\text { moxica }\end{array}$ & $\begin{array}{l}\text { Señora partir querria / a } \\
\text { persona deste mundo }\end{array}$ & SAiob-2O5 (ז26v-I27V) \\
\hline $\mathrm{O} 5 \mathrm{IO}$ & $\begin{array}{l}\text { Diego Palomeque [Juan } \\
\text { de Mena], dezir que fizo } \\
\text { diego palomeque }\end{array}$ & $\begin{array}{l}\text { muerte que a todos } \\
\text { conbidas / a ninguno mal } \\
\text { pecado }\end{array}$ & 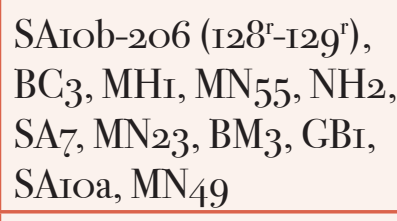 \\
\hline o369 & $\begin{array}{l}\text { Juan de Dueñas, } \\
\text { la misa de amor dicho } \\
\text { por mosen juan de } \\
\text { dueñas }\end{array}$ & $\begin{array}{l}\text { Judica me deus de amor } \\
\text { / dios de benus fasta } \\
\text { muerte }\end{array}$ & $\begin{array}{l}\text { SAIob-207 }\left(\text { I } 29^{\mathrm{r}}-\mathrm{I} 3 \mathrm{O}^{\mathrm{r}}\right) \text {, } \\
\text { МНі }\end{array}$ \\
\hline оI9I & $\begin{array}{l}\text { Juan Agraz, desir que fiso } \\
\text { juan agras a la muerte del } \\
\text { conde nyebla su señor }\end{array}$ & $\begin{array}{l}\text { eçelente rrey señor / syn } \\
\text { tu mano executorya }\end{array}$ & 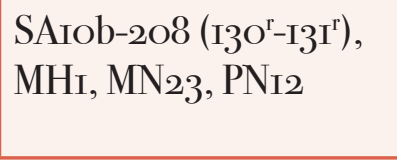 \\
\hline
\end{tabular}




\begin{tabular}{|c|c|c|c|}
\hline I860 & $\begin{array}{l}\text { Juan Agraz, otro dezyr de } \\
\text { juan agras }\end{array}$ & $\begin{array}{l}\text { leeran esta materia / del } \\
\text { grand rrey nuestro señor }\end{array}$ & $\begin{array}{l}\text { SAIob-209 } \\
\left(\mathrm{I}^{\mathrm{r} \mathrm{I}^{\mathrm{r}-\mathrm{V}}}\right)\end{array}$ \\
\hline 0285 & $\begin{array}{l}\text { Juan Alfonso de Baena, } \\
\text { Dezir que envio juan } \\
\text { alfonso de baena al señor } \\
\text { rrey [...] }\end{array}$ & $\begin{array}{l}\text { para rrey tan excelente/ } \\
\text { alto rey ca es fundado... }\end{array}$ & 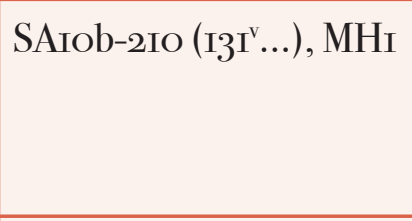 \\
\hline o380 & |-----_----- & $\begin{array}{l}\text {...Syvestistes los } \\
\text { desnudos / prouision de } \\
\text { mi letiçia }\end{array}$ & $\begin{array}{l}\left.\text { SAIob-2II (...II3 } 3^{\mathrm{r}}\right), \mathrm{MH} \text {, } \\
\mathrm{MN}_{55}, \mathrm{SA}_{7}, \mathrm{MN}_{2}\end{array}$ \\
\hline OII2 & $\begin{array}{l}\text { Diego de San Pedro, que } \\
\text { fizo diego de san pedro a } \\
\text { la sepultura de maçias }\end{array}$ & $\begin{array}{l}\text { sepultura de maçias / en } \\
\text { brebe della salir }\end{array}$ & $\begin{array}{l}\left.\text { SAIOb-2I2 (II3 } 3^{\mathrm{V}}-\mathrm{II} 4^{\mathrm{v}}\right) \\
\text { PN6, }\end{array}$ \\
\hline OI92 & $\begin{array}{l}\text { Juan Rodríguez del } \\
\text { Padrón, los goços de } \\
\text { amor que fizo juan } \\
\text { rrodrigez [...] }\end{array}$ & $\begin{array}{l}\text { Ante las puertas del } \\
\text { tenplo / vna gloria los } \\
\text { posea }\end{array}$ & 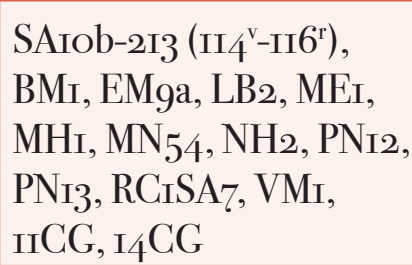 \\
\hline I86I & $\begin{array}{l}\text { Juan de Mena, Copla que } \\
\text { fiço juan de mena a pedro } \\
\text { de mendoşa }\end{array}$ & $\begin{array}{l}\text { gentil señor dalmaçan / } \\
\text { que las toman do las dan }\end{array}$ & SAıob-2I4 (пі6 \\
\hline I862 R I86I & $\begin{array}{l}\text { Pedro de Mendoça, } \\
\text { Respuesta de pedro de } \\
\text { mendoca (sic) }\end{array}$ & $\begin{array}{l}\text { quantos sabios oyran / de } \\
\text { probar mas que podran }\end{array}$ & SAIob-2I5 (II $\left.6^{r}\right)$ \\
\hline ooo6 & $\begin{array}{l}\text { Juan de Mena, Coplas que } \\
\text { hizo juan de mena }\end{array}$ & $\begin{array}{l}\text { guay de aquel onbre que } \\
\text { mira / cada dya vn juan } \\
\text { de mena }\end{array}$ & $\begin{array}{l}\left.\text { SAIob-2I6 (II6r-II } 7^{\mathrm{r}}\right) \\
\text { BMI, LB2 }_{2}, \mathrm{MEI}_{1}, \mathrm{MN}_{54}, \\
\text { PN4, PN8, RCI, VMI, } \\
\text { IICG, I4CG, MHI, NH2 }\end{array}$ \\
\hline I863 & $\begin{array}{l}\text { Juan Agraz, Otro dezir } \\
\text { que fizo juan agras a juan } \\
\text { marmolejo }\end{array}$ & $\begin{array}{l}\text { acordado avemos nos / } \\
\text { como eras de primero }\end{array}$ & SAıob-2I7 (II $\left.7^{\mathrm{r}}\right)$ \\
\hline I864 R I863 & $\begin{array}{l}\text { Juan Marmolejo, } \\
\text { Respuesta de marmolejo }\end{array}$ & $\begin{array}{l}\text { mas que toronbo de piñas } \\
\text { / traes foradado el cuero }\end{array}$ & SAIob-2I8 (II $\left.7^{\vee}\right)$ \\
\hline I865 & $\begin{array}{l}\text { Juan Agraz, Enventario } \\
\text { que fiço juan agraz a } \\
\text { juan marmolejo }\end{array}$ & $\begin{array}{l}\text { mala nueba de la tierra } \\
\text { que la sed vos fara guerra }\end{array}$ & $\begin{array}{l}\left.\text { SAıоb-2I9 (II } 7^{\vee}\right), \text { IICG, } \\
\text { I4 }^{*} \mathrm{JA}, \text { I4CG, I9OB }\end{array}$ \\
\hline I866 R I865 & $\begin{array}{l}\text { Juan Marmolejo, } \\
\text { Respuesta de marmolejo }\end{array}$ & $\begin{array}{l}\text { juan agraz pues abre } \\
\text { e çierra / abesado con } \\
\text { çençerra }\end{array}$ & SAiob-220 (II $\left.7^{\vee}\right)$ \\
\hline $\mathrm{I} 867$ & $\begin{array}{l}\text { Juan Agraz, } \\
\text { otra de juan agraz }\end{array}$ & $\begin{array}{l}\text { A puertas de vn bodegon } \\
\text { / de castilla e de aragon }\end{array}$ & 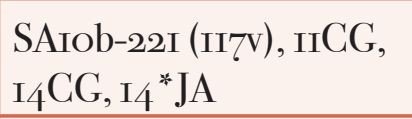 \\
\hline I868 R I867 & $\begin{array}{l}\text { Juan Marmolejo, } \\
\text { Respuesta de marmolejo }\end{array}$ & $\begin{array}{l}\text { por confeso baraton / en } \\
\text { figura de cabron }\end{array}$ & SAiob-222 (II $\left.7^{\vee}\right)$ \\
\hline
\end{tabular}




\begin{tabular}{|c|c|c|c|}
\hline I869 & $\begin{array}{l}\text { Juan Agraz, } \\
\text { otra de juan agraz contra } \\
\text { marmolejo }\end{array}$ & $\begin{array}{l}\text { vn rramo po estandarte } \\
\text { (sic) / e tres mill tranpas } \\
\text { aparte }\end{array}$ & $\begin{array}{l}\left.\text { SAıоb-223 (II } 7^{v}\right), \text { IICG, } \\
\text { I4CG, I4 }{ }^{*} \mathrm{JA}\end{array}$ \\
\hline ı87о R I869 & $\begin{array}{l}\text { Juan Marmolejo, } \\
\text { Respuesta de marmolejo }\end{array}$ & $\begin{array}{l}\text { si punadas se rreparte/ } \\
\text { no ay quien vos desenarte }\end{array}$ & SAIob-224 (II $\left.7^{\vee}\right)$ \\
\hline I87I & $\begin{array}{l}\text { Juan Agraz, } \\
\text { otra de juan agraz }\end{array}$ & $\begin{array}{l}\text { munchos bienes son } \\
\text { vendidos / e lebarbos an } \\
\text { en andas... }\end{array}$ & $\begin{array}{l}\left.\text { SAiob-225 (II } 7^{\vee}\right), \text { IICG, } \\
\text { I4CG, I4 }{ }^{*} \mathrm{JA}\end{array}$ \\
\hline
\end{tabular}

